NASA Technical Memorandum 88915

\title{
Application of Advanced Computational Codes in the Design of an Experiment for a Supersonic Throughflow
} Fan Rotor

Jerry R. Wood, James F. Schmidt, Ronald J. Steinke, Rodrick V. Chima, and William G. Kunik Lewis Research Center Cleveland, Ohio

(NASA-TH-88915) AEPLICATICN CF ADVANCED N87-22630 CCOPUTATICNAL CCDES IN THE LESIGA OP AN EXPERIAENT FOE SOFEESCNIC IHECUGHFLON EAA FCTOR (NASA) $30 \mathrm{p}$ Avail: NIS HC A03/HF AC1 CSCL $01 A \quad \square / 02$

Prepared for the

32nd International Gas Turbine Conference and Exhibit sponsored by the American Society of Mechanical Engineers Anaheim, California, May 31-June 4, 1987 


\title{
APPLICATION OF ADVANCED COMPUTATIONAL CODES IN THE DESIGN OF AN EXPERIMENT FOR A SUPERSONIC THROUGHFLOW FAN ROTOR
}

\author{
Jerry R. Wood, James F. Schmidt, Ronald J. Steinke, \\ Rodrick V. Chima, and William G. Kunik \\ National Aeronautics and Space Administration \\ Lewis Research Center \\ Cleveland, Ohio 44135
}

\section{ABSTRACT}

Increased emphasis on sustained supersonic or hypersonic cruise has revived interest in the supersonic throughflow fan as a possible component in advanced propulsion systems. Use of a fan that can operate with a supersonic iniet axial Mach number is attractive from the standpoint of reducing the inlet losses incurred in diffusing the flow from a supersonic flight Mach number to a subsonic one at the fan face. The data base for components of this type is practically nonexistent; therefore, in order to furnish the required information for assessment of this type $f$ an, a program has been initiated at the NASA Lewis Research Center to design, build, and test a fan rotor that operates with supersonic axial velocities from inlet to exit. This paper describes the design of the experiment using advanced computational codes to calculate the unique components required.

The fan rotor has constant hub and tip radii and was designed for a 2.7 pressure ratio with a tip speed of $457 \mathrm{~m} / \mathrm{sec}$. The rotor was designed using existing turbomachinery design and analys is codes modified to handle fully supersonic axial flow through the rotor. A two-dimensional axisymmetric throughflow design code plus a blade element code were used to generate $f$ an rotor velocity diagrams and blade shapes. A quasithree-dimensional, thin shear layer Navier-Stokes codes was used to assess the performance of the fan rotor blade shapes. The final design was stacked and checked for three-dimensional effects using a three-dimensional Euler code interactively coupled with a two-dimensional boundary layer code.

A translating nozzle was designed to produce a uniform, parallel flow to the fan up to the design axial Mach number of 2.0. The nozzle was designed with the three-dimensional Euler/interactive boundary layer code. The nozzle design in the expansion region was analyzed with a three-dimensional parabolized viscous code which corroborated the results from the Euler code. A translating supersonic diffuser was designed using these same codes.

\section{INTRODUCTION}

Recent renewed interest in high-speed flight has focused attention on possible power plants to sustain efficient supersonic cruise or to act as boosters to accelerate a vehicle to moderate supersonic velocities where transition might take place to propulsion by a subsonic ramjet for subsequent acceleration to hypersonic velocities. One such power plant was discussed by Boxer (1) who proposed a high bypass ratio turbofan engine/ramjet combination which utilized a variable pitch supersonic axial inflow fan. Cascade tests were performed with supersonic inflow air operating at $2144 \mathrm{~K}$ and adequate cooling was maintained. Spin pit tests were also conducted on a single blade to test a proposed mechanism for varying the pitch of the $f$ an blades at the design tip speed of $448 \mathrm{~m} / \mathrm{sec}$ with good success.

Cycle studies have indicated that substantial improvements can be obtained by using a fan that was capable of accepting a supersonic axial component in a turbofan engine at supersonic cruise conditions. Ferri (2) was the first to point out the potential advantages of eliminating the subsonic portion of the supersonic inlet and providing a fan capable of accepting supersonic axial inflow.

Franciscus (3) compared the performance of several supersonic throughflow fan engines to a reference turbofan engine for a Mach 2.32 al1 supersonic cruise mission and concluded that use of a supersonic throughflow fan equipped engine could reduce specific fuel consumption by 12 precent which could lead to an improvement in range of 20 percent. Tavares (4) considered a mission for a supersonic transport operating at Mach 2.7 and concluded that a fan efficiency of 68 percent would be necessary to have performance advantage over a turbojet engine with the same core. All of the cycle studies to date have suffered from a severe lack of experimental data to confirm assumptions concerning the fan performance. Only two experiments dealing with supersonic axial inflow to an axial flow rotor are known to the authors. Savage (5) 
showed a single plot of efficiency versus pressure ratio for a transonic rotor which was operated at tip speeds considerably above the design value in conjunction with a Mach 1.5 annular flow nozzle to study the rotor starting characteristics with a shadowgraph technique. The most thorough experiment to date for this type of rotor was conducted by Breugelmans (6). He designed and tested an isolated rotor with a design inlet axial Mach number of 1.5. Because of a mechanical failure, extensive data was not taken; however, the rotor did start as anticipated and a total-total pressure ratio of about 2 at 80 percent design speed was attained. Based upon the measured data the rotor appeared to be operating with an internal shock which produced subsonic axial flow out of the rotor.

Because of the possible advantages of incorporating a supersonic throughflow fan into the propulsion system for high speed vehicles, NASA Lewis embarked upon a program to develop the computational capability to analyze and design turbomachinery with supersonic axial inlet Mach numbers. Recent developments in turbomachinery analys is codes (Denton (7), Chima (8)) and modern high speed computers have combined to provide the turbomachinery designer with sophisticated computational tools to guide him in attaining a desirable design. The state-of-the-art, however, in computational capability in turbomachinery would suggest that even though a great deal of the physics of the flow process is modeled, not all of the details of the flow $c$ an be resolved. Thus, computational tools available today must be thoroughiy tested against experiments to "calibrate" them for design purposes. The intent of this paper is to describe the design using advanced computational codes of an experiment to investigate the flow in a supersonic throughflow fan rotor. An experimental program is anticipated that will obtain both overall performance and detailed internal flow patterns to provide necessary "calibration" data for this type of turbomachine.

\section{COMPUTATIONAL CODES}

A variety of codes ranging from a one-dimensional meanline compressor code to a three-dimensional viscous parabolized code were used to design the fan stage and several critical elements of the facility. It was necessary to modify all the turbomachinery codes to handle axial supersonic velocities since their traditional use has been for subsonic axial flow. All these codes had been previously tested against turbomachinery data in the relative Mach number range around 1.4 but had not been applied in the range of interest for this paper. Since no database existed to adequately test the codes at the Mach number range of interest, where possible, codes using different algorithms were used to obtain solutions on the same element in order to increase confidence in the final design. The codes used are described in the following sub-headings:

\section{Meanl ine code (STGSTK):}

The STGSTK code by Steinke (9) is a onedimensional inviscid code used to estimate off-design performance once design point performance is estimated. The code uses the estimated design point performance and correlations based upon transonic blade element data to predict the off-design performance. The code was modified to allow calculation of single blade rows, stages, and counter rotating rotors having supersonic axial velocity. The results from STGSTK were used to check matching of the facility speed and power requirements and to give a perspective on how an operating line might look for this type of turbomachine.
Axisymmetric Compressor Design Code (CDP):

The CDP code by Crouse and GorreTा (10) uses the streamline curvature method to compute velocity diagrams at the blade edges for two-dimensional inviscid axisymmetric flow. This code provides flow solutions at the leading and trailing edge of the blades which satisfy the desired pressure ratio, mass flow, and radial equilibrium. The code also stacks an arbitrary blade shape from hub to tip and prints output data for subsequent analysis by more advanced codes. The code requires input for blade element incidence, loss, and deviation anqle. Each subsequent blade element which satisfies the input conditions is described using fourth order polynomials for the blade angle and thickness distributions. CDP generates blade element geometry which can be used in a detailed blade element analysis code. The blade geometry can be iterated until the deviation predicted by the viscous code and the deviation used in CDP are the same.

The CDP was modified to calculate supersonic axial flow; however, because the code uses the streamline curvature method it was necessary to incorporate damping on the calculated curvatures in order to obtain converged solutions.

\section{Thin-shear-layer Viscous Code (RVCO3):}

The RVCO3 code by Chima (8) solves the Euler and thin shear layer Navier Stokes equations for a quasithree-dimensional flow. The convergence is enhanced by use of variable timesteps, multi-gridding and by vectorization for application to the NASA Lewis Cray XMP. The code uses a C-type grid which is generated by a modified form of the GRAPE code grid generator by Sorenson (11). The RVCO3 was used as a "numerical test cell" to screen blade designs and aid the designer in evaluating the desirability of one blade design over another.

The RCV03 is relatively new but results (12) have compared well to laser anemometry measurements made at NASA Lewis on a transonic compressor rotor as indicated in Fig. 1. The experimentally measured static pressure was used as the downstream boundary condition on RVC03. The shock location and downstream Mach number contours predicted by the code aqree quite well with the data. RVCO3 was adapted for supersonic axial flow by holding the inlet conditions constant and extrapolating the flow quantities to the downstream boundary.

Three-dimensional Euler Code with Interactive Twodimensional Boundary Layer Code (D3DVBL):

The D30VBL code consists of the three-dimensional finite volume code developed by Denton (7) and an interactive boundary layer calculation (13) which is continually updated as the time unsteady solution proceeds to a final steady state value. The method models only the displacement effect of the boundary layer on the flow by injecting additional mass into the flow path in the proper proportion to simulate a physical displacement of the wall surface equal to the calculated displacement thickness. The external conditions for the boundary layer are taken as the velocity at the blade surface and the boundary layer is assumed to be affected only by the component of velocity which lies along a streamwise grid line i.e. no strong threedimensional flows are present in the channel. The original boundary layer routine was a simple solution to the von Karman integral equation using a constant shape factor and skin friction coefficient which was shown by Pierzga and Wood (14) to significantly improve the calculated results when compared to experimental 1 aser anemometry data on a transonic fan. In order to better model the boundary layer the method of Sasman 
and Cresci (15) as developed by McNally (16) for turbulent boundary layers was added to the code by Liu (17). The method solves the momentum and moment of momentum integral equations for a compressible turbulent boundary layer to obtain the momentum thickness and shape factor. The boundary layers are always assumed to be turbulent. The original paper by Sasman and Cresci modeled the integral of the shear stress through the boundary layer as a function of incompressible shape factor and the incompressible skin friction coefficient. Comparison of the results of the Sasman and Cresci model to flows with large decelerations where the incompressible shape factor is large indicates that separation is predicted much too early by the method. Wood and Schmidt (20) modified the expression for the shear stress integral so that the prediction of shape factor growth near separation more closely modeled data (see for example Moses' Case 5 in the Stanford conference on incompressible turbulent boundary layers (19)). Calculations for flows which were not near separation indicated the modified expression did not adversely affect the results. All the results obtained with the D3DVBL code presented herin for the nozzle, fan and diffuser design use the Sasman and Cresci equations with the modification by Wood and Schmidt.

The D3DVBL code was used to check the threedimensionality of the rotor flow after the design was completed. It was shown by Wood, Strazisar, and Simonyi (20) that the D3DVBL code prediction of shock three-dimensionality agreed very well with laser anemometry data taken on a transonic fan stage. In order to confirm that differences between the quasi-threedimensional results from the RVCO3 code and the D3DVBL code were indeed due to three-dimensional effects, the D3DVBL code was run on the mean and tip section in a two-dimensional mode (i.e. only a very thin streamsheet was analyzed with the hub and tip boundary layer calculations turned off). These two-dimensional calculations were compared to the results from the RVCO3 code and the D3DVBL three-dimensional calculations to assess whether three-dimensional affects were a significant factor in the final design.

The D3DVBL code was modified so that the inlet axial velocity at the hub was held constant and the gradient of the radial velocity in the streamwise direction was constant. Radial equilibrium with the assumption of no streaml ine curvature was used to establish the pressure gradient from hub to tip at the inlet plane and thus the velocity field. No downstream condition was imposed on the solution for flow with all supersonic axial velocities. The code may also be run with a downstream static pressure imposed to calculate a shock-in-rotor flow when the incoming axial flow is supersonic. The supersonic throughflow fan tested by Breugelmans (6) was analyzed with the D3DVBL code. The nonaxisymmetric hub of the test rotor was modeled as an axisymmetric hub with the same contraction ratio across the rotor. The results of the calculation for the rotor are shown in Fig. 2 for the tip section. The calculations indicate that the oblique shock from the leading edge is contained inside the blade passage with no strong shocks emanating from the trailing edge. During modification of the RVCO3 and D3DVBL codes for supersonic throughflow, a design with a typical transonic rotor tip solidity and an inlet axial Mach number of 1.5 was analyzed. MCA blades with typical transonic maximum thickness to chord ratios were used. The results of the analysis using the RVCO3 code and the D3DVBL. code run as a two-dimensional code on the section and as a three-dimensional code on the entire rotor are shown in Fig. 4. Because of the solidity chosen, the wave system is not contained inside the passage and shocks pass into the downstream flow tield. The agreement between the RVCO3 and D3DVBL codes is excellent.

Three-dimensional Parabolized Viscous Supersonic Code (PEPSIS):

The PEPSIS code is a three-dimensional parabolized viscous code which has been used extensively at NASA Lewis to calculate supersonic flows for mixed compression inlets and benchmark-type experiments (21,22). Results from the code for flows at supersonic Mach numbers similar to those encountered in the nozzle and diffuser show that the viscous layers and the shock/ boundary layer interaction effect are well predicted by the code. Details of the code development are described in the paper by Buggein (23). The code was used to analyze the final designs for the translating nozzle and diffuser. Several diffuser designs which the D3DVBL code indicated were separated (incompressible shape factor exceeding 2.4) were analyzed with the PEPSIS code. In all cases the PEPSIS calculations became unstable in approximately the same location where separation was predicted by the D3DVBL code.

\section{OVERALL FAN DESIGN CONDITIONS}

Since the intent of the research program on this supersonic throughflow fan is to develop the computational technology to design/analyze this unusual type of turbomachine for possible future applications, there were several overall guidelines which impacted the final design. They are as follows:

1. Since viscous effects can be important in terms of the secondary flows generated when the shock waves interact with the hub and tip boundary layers and a three-dimensional viscous code is not available for turbomachinery desian, it was decided to limit possible severe three-dimensional effects by maintaining the hub and tip radi $i$ constant through the rotor. This has the additional advantage that the spacing between the rotor and a subsequent stator design can be easily varied to determine its effect on stage performance.

2. A moderate overall pressure ratio at moderate tip speed was selected to be representative of the pressure ratio that might be required for a high-speed power plant but not so agressive as to require large blade turning for this initial experiment.

3 . The blade span should be representative of that required for possible inlet matching but be large enough to allow detailed spanwise surveys with laser anemometry.

The overall facility showing the location of the translating nozzle, fan rotor and translating diffuser is shown in Fig. 5. The inlet plenum can be connected to an atmospheric intake or to the NASA Lewis central air supply system. By means of an upstream throttle valve, the inlet plenum pressure can be varied from sub-atmospheric up to several atmospheres. The collector can be connected to either an atmospheric exhaust or to the NASA Lewis altitude exhaust system. The rotor has a design pressure ratio of 2.7 , an inlet axial Nach number of 2.0 and a tip speed of $457.2 \mathrm{~m} / \mathrm{sec}$. The estimated design absolute Mach numbers are shown in Fig. 6. Because there is no contraction in the flow path the Mach number increases from the inlet value of 2.0 to a value at exit of about 3.1 at the hub and 2.7 at the tip. These Mach number distributions were calculated from the CDP code. The streamlines predicted by the CDP code are shown in Fig. 7 and were used to generate streamsheet thickness distributions for the RVCO3 viscous code. 
Once design point performance was estimated, the STGSTK program was used to estimate the offdesign performance map shown in Fig. 8 for a stage. Supersonic axial Mach numbers occur at speeds above 60 percent of design. The locii of operating points for zero incidence to the suction surface of the meanline blade is shown on the map to indicate a possible operating line for the experimental test. Envelope lines at positive and negative $3^{\circ}$ of incidence are also shown on the figure to indicate the range available over a $6^{\circ}$ incidence change. Further analys is by the RVCO3 would be necessary to indicate whether or not this range is reasonable. This operating line would certainly require a variable nozzle and might possibly require variable blading as well.

\section{TRANSLATING NOZZLE DESIGN}

In order to test the fan over a range of inlet Mach numbers from subsonic to the design inlet value of Mach 2, it was necessary to design an annular nozzle that would deliver a uniform, parallel flow at the fan face. Since the facility selected to serve as the test bed for the fan used an overhung bearing mount, it was desirable to hold the axial length and movement of the nozzle to a minimum. The D3DVBL code was used for the design since it allowed calculation of the entire flow field from very low subsonic Mach numbers to the design value of 2. The shroud portion of the nozzle starts at the inlet plenum radius of $60.96 \mathrm{~cm}$ and is faired into a superellipse which subsequently fairs into the constant radius section in front of the $f a n$. This allowed a great deal of flexibility in balancing between the requirement for a short stroke on the nozzle and control of the surface curvatures. The lower surface started at the sting radius of $9.525 \mathrm{~cm}$ and was faired into a point which was determined from the required throat area calculated from one-dimensional considerations to produce the desired nozzle Mach number. A control point was used with a cubic spline fairing to determine the distribution of the wall slope from the throat to the constant radius hub section. An initial geometry based primarily upon the one-dimensional area ratio was analyzed with the D3DVBL code. If an acceptable solution was not obtained, the initial geometry was perturbed and the previous solution used as the initial starting point for the next solution. Depending upon the degree of change in the geometry, the next solution could be obtained in a relatively short number of timesteps. After obtaining a satisfactory solution with the DSDVBL code, the nozzle was analyzed using the PEPSIS viscous code. The code is for all supersonic flow so the results from the D3OVBL code just past the throat were used as the initial starting profile. The results from the D3DVBL analysis for the entire nozzle are shown in Fig. 9 along with the results obtained with the PEPSIS viscous code in the supersonic region. The flow smoothly accelerates into the throat and expands rapidly with a compression wave emanating from the hub where the wall begins to turn back toward axial. The wave is canceled on the shroud wall and the flow attains a Mach number slightly higher (2.08) than the desired value of 2.0. Comparison of the D3DVBL code results with the PEPSIS viscous code results shows that the agreement is excellent. The clustering of contour lines near the walls in the viscous code results indicates the extent of the wall boundary layers.

Figure 10(a) shows the distribution of Mach number versus spanwise distance at the fan face. The freestream values predicted by the two codes agree very well with the viscous code indicating boundary layer thicknesses on each wall of about 10 to 14 percent of the passage height. Also shown in the figure is the distribution of Mach number relative to the fan blade. This was obtained by adding the blade speed at any radial location to the axial velocity predicted by the viscous code. Figure 10 (b) is a plot of the difference in the flow angle relative to the blade obtained with the inviscid profile from the Euler code and from the viscous profile. This represents the skewness in the relative velocity profile as a result of the inlet boundary layer. This effect is, of course, present in all turbomachine rotors, but for this case the skewness occurs at Mach numbers of about 1.6 or higher and has the potential to trigger flow separation from the blade which could possibly result in an unstart of the rotor.

In order to insure the nozzle would deliver a desirable flow over the range of translation, the geometries for six different axial settings of the translating hub part of the nozzle were analyzed with the D3DVBL code. Figure 11 shows the results obtained. Each case analyzed showed that the flow delivered by the nozzle was uniform. The results are compatible with $f$ an speed 1 ines from 70 to 102 percent of design speed which have supersonic axial inflow as presented in Fig. 8.

Mechanical considerations dictated that the nozzle design on the hub would have to be modified to end in about a $7^{\circ}$ wedge instead of the smoothly varying slope used in the final design. Analysis of this modification predicted a wave emanating from the intersection of the translating part with the stationary part with a Mach number variation across the wave of about 0.1 which was judged acceptable for the experiment.

\section{DETAILED FAN ROTOR BLADE DESIGN}

The detailed fan rotor design was done by Schmidt (24) using the CDP and RVCO3 codes described earlier. Details of the fan rotor design such as deviation, blade number, blade solidity, and blade thickness resulted from analys is of prospective blade shapes using the RVCO3 code for guidance. Five sections from hub to tip were designed with the RVCO3 code and stacked using the CDP code to form a three-dimensional blade. The mean section designed by Schmidt was analyzed with the grid shown in Fig. 12. The results shown in Fig. 13 indicate that the wave system is contained inside the passage and the flow exits the blade smoothly. The static pressure distribution closes at the trailing edge indicating that the flow on both sides of the blade has been turned equally. Details of the bow shock at the leading edge and the flow vectors at the trailing edge are shown in Fig. 14 .

The near-hub blade section was analyzed by Schmidt with the RVCO3 code at $+5^{\circ}$ and $-5^{\circ}$ of incidence to the suction surface. No global flow breakdown which might indicate a possible unstart situation was indicated. These offdesign calculations indicate that the incidence range envelope of $+3^{\circ}$ to $-3^{\circ}$ shown in Fia. 8 is reasonable.

In order to check the flow three-dimensionality, the final stacked blade from the CDP program was analyzed with the D3DVBL code. As indicated earlier the D30VBL code was run on a two-dimensional section so that comparisons for three-dimensional effects would not be code-dependent. Static pressure distributions for the mean section are shown in Fig. 15. Both twodimensional and three-dimensional results from the D3DVBL code show slightly more compression on the pressure surface at about 20 to 40 percent chord than do the results for the RVCO3 code. The difference in static pressures is apparently due, primarily, to the 


\section{ORIGINAL PAGE IS
OF PROD N!IALITY}

viscous treatment used. RVCO3 allows transition from laminar to turbulent flow whereas D30VBL assumes a fully turbulent boundary layer. Calculations using both codes with no viscous effects included yielded static pressure distributions which were in much better agreement (6.9 percent difference versus 19 percent difference with viscous effects). The results for the D3DVBL code on the mean section run in the twodimensional and three-dimensional mode agree closely except on the suction surface from about 75 percent chord to the trailing edge. This difference can be attributed to the three-dimensional nature of the flow. It is obvious that there are no significant threedimensional effects present. Three-dimensional effects in terms of pressure-driven secondary flows where the endwall boundary layers are subjected to transverse pressure gradients are not calculated by the D3DVBL code and cannot be estimated for this rotor. The predicted relative Mach number contours for the mean section using the RVCO3 code and the D3DVBL code are shown in Fig. 16. The results from D3DVBL are for the threedimensional calculations on the full rotor blade. The exit Mach number is about 2.6 for both codes with the overall agreement being quite good. The three-

dimensional nature of the flow is indicated in Fig. 17 which shows the relative Mach numbers calculated with D3DVBL on three meridional surfaces. The only appreciable three-dimensional effect is on surface 3 (the suction surface) where the shock is leaning in the meridional plane at about $30^{\circ}$ from the radial direction. The obliquity of the shocks in the blade-toblade plane significantly reduce the effect of the radial lean. The grid used for the three-dimensional calculations is also shown in the figure. The twodimensional solution with D3DVBL was run with the same blade-to-blade grid as used for the three-dimensional calculation. The growth in hub and shroud boundary layer displacement thickness as calculated at mid-gap using the D3DVBL code is shown in Fig. 18. The calculated increase across the rotor is about 50 percent of the inlet value. It should be noted that the endwall region contains some very complex flows which are being modeled by a two-dimensional boundary layer method and that the calculated boundary layer growth serves only as an indicator of the level of blockage to be expected. A full treatment of this region would obviously require a three-dimensional viscous analysis.

Total conditions across the rotor as predicted by the RVCO3 and D3DVBL codes are shown in Fig. 19. The freestream total-total pressure ratio predicted by the RVCO3 code is about 2.9 to 3.4 with the integrated value which includes the wake at the downstream boundary being about 2.82. The D3DVBL code prediction of total-total pressure ratio is about 2.7 to 3.1. Both calculations indicate that the rotor pressure ratio will be achieved.

In order to assess the impact of blade number, the number of blades was changed from the design value of 58 to 54. The results (Fig. 20) from the D3DVBL code run on the rotor indicate that the shock on the suction surface increases in strength and is not fully contained on the tip section. This could produce shocks from the trailing edge which would propagate downstream.

\section{TRANSLATING DIFFUSER DESIGN}

Since it was desired to operate the fan over its entire operating range from subsonic inlet/subsonic outlet to supersonic inlet/subsonic outlet to supersonic inlet/supersonic outlet, it was necessary to design a diffuser capable of operating over this range.
The design was compounded considerably by a restriction on available length and maximum movement which would be available without a major redesign of the experimental facility. However, since static pressure in the downstream collector can be maintained at about 0.21 Bar with an exhauster, it is not necessary for the diffuser to recover a significant amount of the incoming dynamic head. Given the restrictions on the geometry and the range, it was decided to design the the diffuser to recover only a moderate amount of dynamic head with the main goal being to maintain a started diffuser over the Mach number range from 1.4 to the design rotor out let values of about 3.1 at the hub and 2.7 at the tip. The predicted amount of swirl in the rotor outlet air varies from about $27^{\circ}$ at the hub to $21^{\circ}$ at the tip. The diffuser was designed for rotor exit conditions since the initial experiment is to be conducted without the stator in place.

As in the case of the nozzle design the diffuser was designed using a basic geometry generating program and the D3DVBL code. The blockage at the inlet to the diffuser was assumed to be the same as that calculated for the inlet to the rotor since no experimental data exists for endwall blockage growth through a supersonic throughflow fan. It was felt that any increase in blockage could be handled with the variable geometry. The translating part of the diffuser makes up the hub contour from just downstream of the blade row to the inlet of the collector. A $6^{\circ}$ wedge was used to begin the translating section and to initiate the first oblique shock. This wedge angle was chosen because the shock at a $6^{\circ}$ deflection should remain attached down to a Mach number of about 1.28. At this Mach number the shock should detach from the wedge and the flow should shock to subsonic through a normal shock near the wall. The static pressure rise across the shock at 1.28 should not be strong enough to cause boundary layer separation. Boundary layer bleed will be provided at the junction of the translating part and the stationary part to help stabilize the boundary layer and avert a gross flow separation. The results obtained with the D3DVBL code and the results obtained with the PEPSIS viscous code using the design fan rotor exit Mach number and flow angle distributions from hub to tip as upstream conditions are shown in Fig. 21. The oblique shock is not canceled on the shroud because the shroud contour begins to increase in radius just upstream of where the wave hits. This was necessary because otherwise the restriction on axial movement would lead to a terminal shock occurring in the converging portion of the diffuser at the desired lower operating limit of Mach 1.4. The second wave system emanating from the hub results from transition from the $6^{\circ}$ wedge to a modified circular arc used to control the area distribution and turn the flow into the collector. As can be seen the agreement between the two numerical results are excellent with a Mach number of about 1.8 predicted at the collector inlet by both codes. The dark areas near the walls for the Navier-Stokes code results indicate the extent of the boundary layers. Both solutions were obtained with the design swirl anticipated at the exit of the rotor.

Since the endwall boundary layer growth across the rotor is not known with certainty, an offdesign calculation was performed with the D3DVBL code. The inlet boundary layer displacement thickness was doubled on both walls and the design geometry analyzed. The results are shown in Fig. 22. The solution was not stable as a result of the formation of a terminal shock in the diffuser near the collector inlet. The calculations were restarted from the solution shown and allowed to continue. This resulted in a normal shock moving 
through the diffuser into the constant area section. The translating hub was mover $0.508 \mathrm{~cm}$ and the calculations were restarted with the same inlet blockage and the diffuser remained started as indicated in the figure. No calculations were made at axial movements less than $0.508 \mathrm{~cm}$ since the numerical results indicated that the diffuser could be maintained in a started condition.

The offdesign results obtained at Mach 1.4 are shown in Fig. 23. As can be seen in the contour plot the Mach number behind the first oblique shock is 1.25 which indicates that a terminal shock would form if the wave were allowed to reflect from a constant radius tip. This offdesign flow point as mentionaed previously made it necessary to begin increasing the tip radius further upstream than desired for the design point operation in order to keep the diffuser started for the Mach 1.4 condition. The calculation is for an axial movement of $5.08 \mathrm{~cm}$. The results for an axial movement of $4.445 \mathrm{~cm}$ indicated a terminal shock did form and move upstream into the constant area section. Initial research runs will be conducted with only the nozzle and diffuser installed in order to check the operating characteristics of each component. Consequently, these two calculations were run with no inlet swirl to the diffuser.

The design geometry was also analyzed with the expected collector pressure obtainable with the altitude exhaust system imposed as a downstream boundary condition for the D3DVBL code. The results indicated that the diffuser Mach contours were acceptable for subsonic operation. Sonic conditions were predicted at a location just before the collector inlet with a Mach number of about 0.3 in the constant area section.

\section{CONCLUDING REMARKS}

This paper has described the use of advanced computational codes to design an experiment to study a supersonic axial inflow fan rotor in detail. The philosophy taken in order to maximize the possibility of success of the experiment was to perform duplicate calculations using different codes. Where feasible, an existing supersonic viscous code was used to check the design of the experimental components. Application of a quasi-three-dimensional viscous code and a threedimensional Euler code with an interactive twodimensional boundary layer code to model the viscous effects for the supersonic throughflow fan rotor has resulted in almost identical solutions for the blade elements. The three-dimensional code indicated that no significant three-dimensional effects due to shock lean in the meridional plane were present.

Use of advanced codes which mode? much of the physics of the flow in this experiment - but certainly not all of it - to "test" various configurations before commitment to hardware, has the potential to significantly reduce the time and expense required to develop the technology to produce high-efficiency supersonic throughflow components for advanced propulsion systems. In order to gain confidence that the physics is modeled properly in the codes, it is necessary to conduct experiments such as the one anticipated to collect detailed internal flow data which will help us to assess the accuracy of the codes and to understand the physics of this unique turbomachinery component.

\section{REFERENCES}

1. Boxer, E., "The Variable-Pitch Supersonic Inflow Compressor and Its Application in a Hypersonic Engine," Conference on Hypersonic Aircraft Technology, NASA SP-148, 1967, pp. 401-416.
2. Ferri, A., "Problems Related to Matching Turbojet Engine Requirements to Inlet Performances as Function of Flight Mach Number and Angle of Attack," Air Intake Problems in Supersonic Propulsion, J. Fabri, ed., AGARDograph No. 27, AGARD, France, 1956.

3. Franciscus, L.C., "Supersonic Through-Flow Fan Engines for Supersonic Cruise Aircraft, " NASA TM-78889, 1978.

4. Tavares, T.S., "A Supersonic Fan Equipped Variable Cycle Engine for a Mach 2.7 Supersonic Transport," NASA CR-177141, 1985.

5. Savage, M., Boxer, E., and Erwin, J.R., "Resume of Compressor Research at the NACA Langely Laboratory," Journal of Engineering for Power, Vo1. 83, No. 3, July 1961, pp. 269-285.

6. Breugelmans, F.A.E., "The Supersonic Axial Inlet Component in a Compressor," ASME Paper 75-GT-26, Mar. 1975.

7. Denton, J.D., "An Improved Time-Marching Method for Turbomachinery Flow Calculations," Journal of Engineering for Power, Vol. 105, No. 3, July 1983, pp. 514-524.

8. Chima, R.V., "Development of an Explicit Multigrid Algorithm for Quasi-Three-Dimensional Viscous Flows in Turbomachines," AIAA Paper 86-0032, Jan. 1986.

9. Steinke, R.J., "STGSTK: A Computer Code for Predicting Multistage Axial Flow Compressor Performance by a Meanline Stage Stacking Method," NASA TP-2020, 1982.

10. Crouse, J.E. and Gorrell, W.T., "Computer Program for Aerodynamic and Blading Design of Multistage Axial-Flow Compressors," NASA TP-1946, 1981.

11. Sorensen, R.L., "A Computer Program to Generate Two-Dimensional Grids About Airfoils and Other Shapes by the Use of Poisson's Equation," NASA TM-81198, 1980 .

12. Chima, R.V., "Inviscid and Viscous Flows in Cascades With an Explicit Multiple Grid Algorithm," AIAA Journal, Vol. 23, No. 10, 0ct. 1985, pp. $1556-1563$.

13. Denton, J.D., Lecture Notes, ASME Turbomachinery Institute Course on Fluid Dynamics of Turbomachinery, Ju1y 18-27, 1983.

14. Pierzga, M.J. and Wood, J.R., "Investigation of the Three-Dimensional Flow Field Within a Transonic Fan Rotor: Experiment and Analysis," Journal of Engineering for Gas Turbines and Power, Vol. 107, No. 2, April 1985, pp. 436-449.

15. Sasman, P.K. and Cresci, R.J., "Compressible Turbulent Boundary Layer With Pressure Gradient and Heat Transfer," AIAA Journal, Vol. 4, No. 1, Jan. 1966, pp. 19-25.

16. MCNally, W.D.,"FORTRAN Program for Calculating Compressible Laminar and Turbulent Boundary Layers in Arbitrary Pressure Gradients, " NASA TN D-5681, 1970. 
17. Liu, J.S., "Numerical Models for Transonic Inlet Rotor Stages of Axial Flow Compressors," M.S. Thesis, Case Western Reserve University, 1984.

18. Wood, J.R., Strazisar, A.J. and Simonyi, P.S. "Shock Structure Measured in a Transonic Fan Using Laser Anemometry," Presented at the AGARD Symposium on Transonic and Supersonic Phenomena in Turbomachines Propulsion and Energetics Panel 68th Specialists Meetings, Munich, Sept. 1986. (NASA TM-88910).

19. Coles, D.E. and Hirst, E.A., eds., "Proceedings of the AFOSR-IFP-Stanford Conference on Computation of Turbulent Boundary Layers - 1968, Stanford University, Aug. 1968. (AFOSR-69-2713TR, -696082)

20. Wood, J.R. and Schmidt, J.R., NASA Lewis Research Center, Cleveland, $\mathrm{OH}$, Personal Communications.
21. Anderson, B.H., "Three Dimensional Viscous Design Methodology for Advanced Technology Aircraft Supersonic Inlet Systems," AIAA Paper 84-0194, Jan. 1984.

22. Anderson, B.H. and Benson, T.J., "Numerical Solution to the Glancing Sidewall Oblique Shock Wave/Turbulent Boundary Layer Interaction in ThreeDimensions," AIAA Paper 83-0136, January 1983.

23. Buggein, R.C., McDonald, H., Levy, R. and Kreskovsky, J.P., "Development of a ThreeDimensional Supersonic Inlet Flow Analysis," NASA CR-3218, 1980.

24. Schmidt, J.F., "Design of a Supersonic Through-F low Fan Stage," NASA TM- 88908. 


\section{ORIGINAL PAGE IS \\ OF POOR QUALITY}

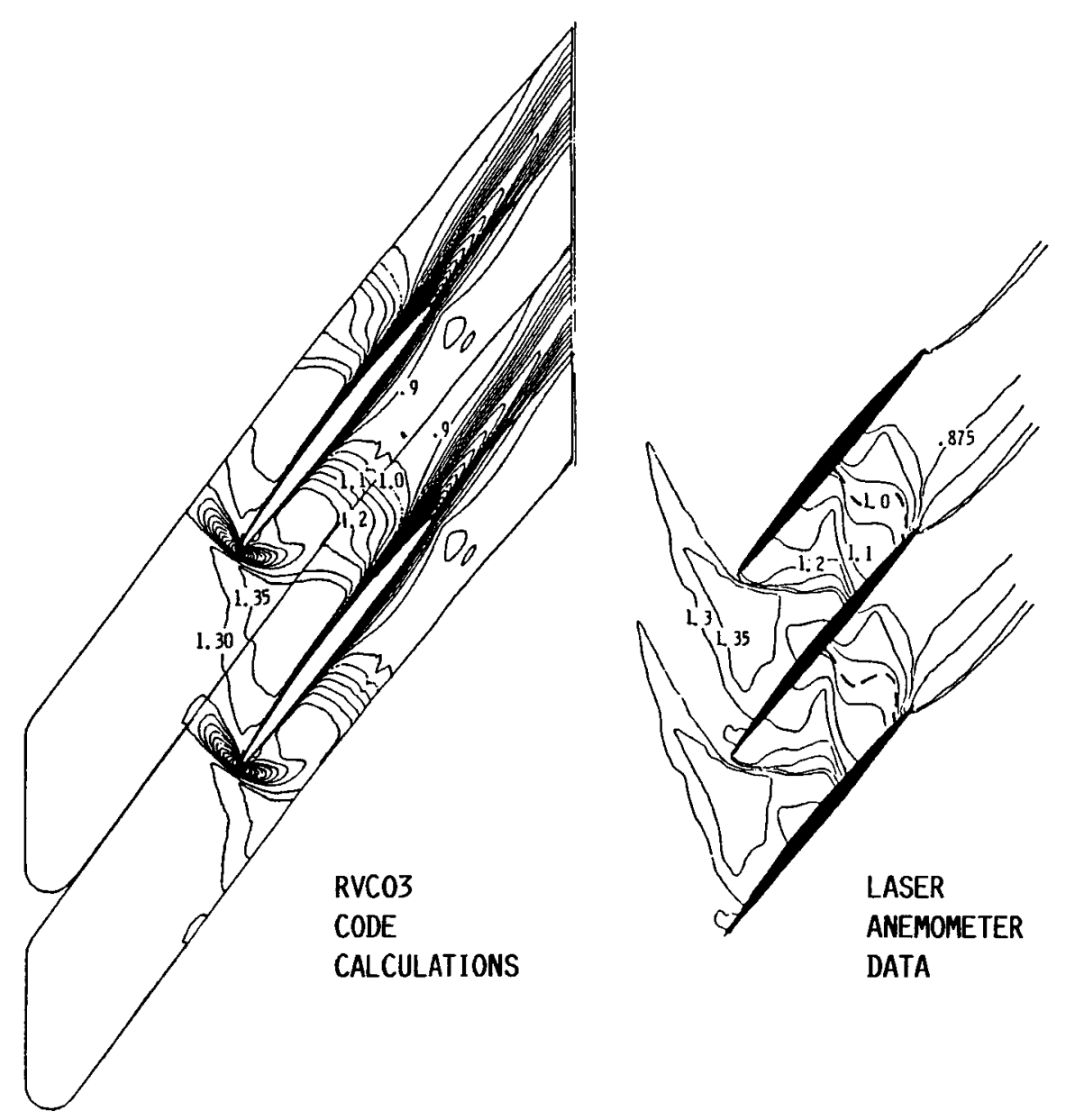

FIGURE 1.- RELATIVE MACH NUMBER CONTOURS FOR NASA ROTOR 33 FROM RVCO3 CODE (USING EXPERIMENTAL BACK PRESSURE FOR DOWNSTREAM BOUNDARY CONDITION) COMPARED TO LASER ANEOMETER DATA. 


\section{ORIGINAL PAGE IS OF POOR QUALITY}

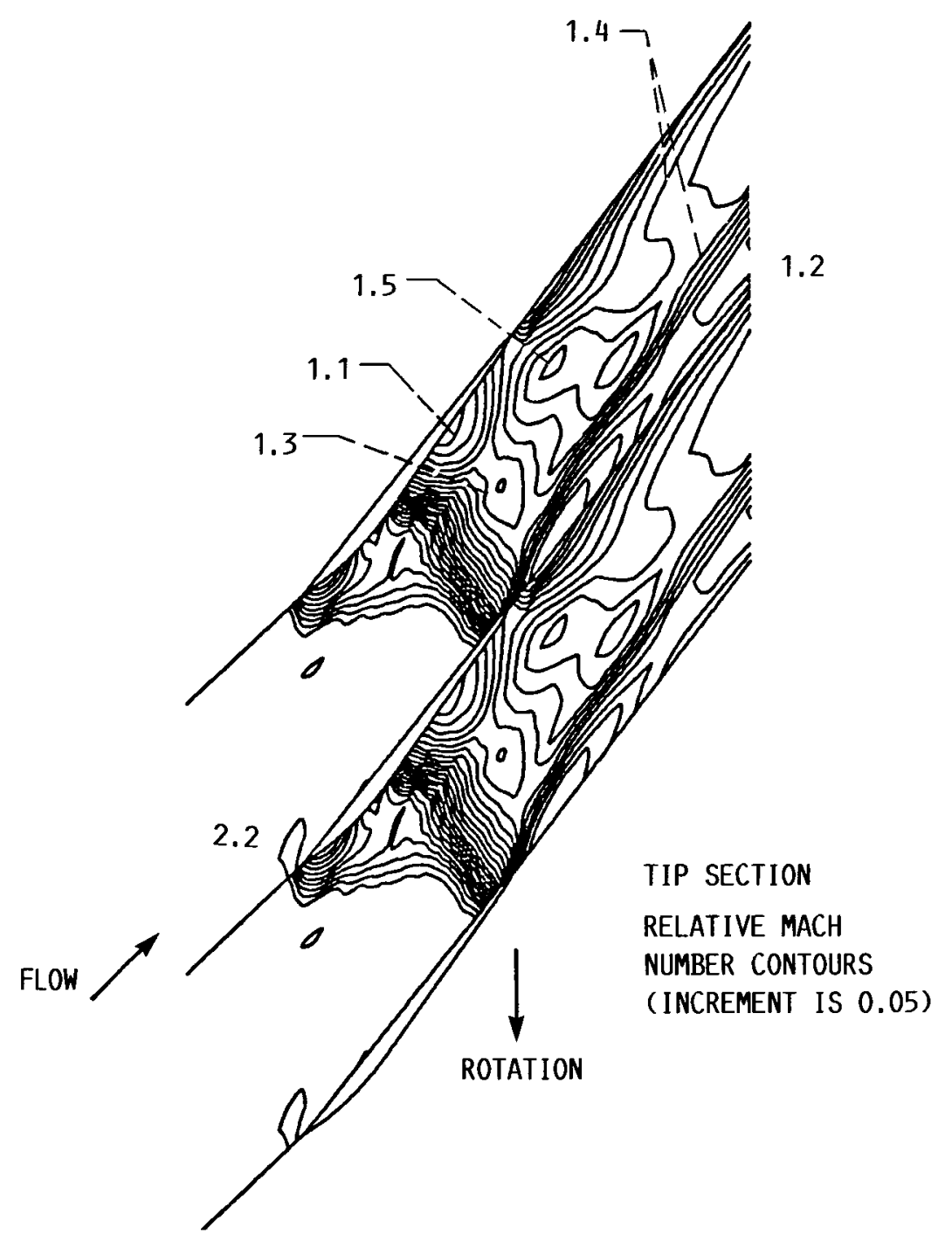

FIGURE 2. - CALCULATED RESULTS FROM THE D3DVBL CODE ON THE SUPERSONIC THROUGHFLOW ROTOR TESTED BY BRUEGELMANS (REF, 6). 


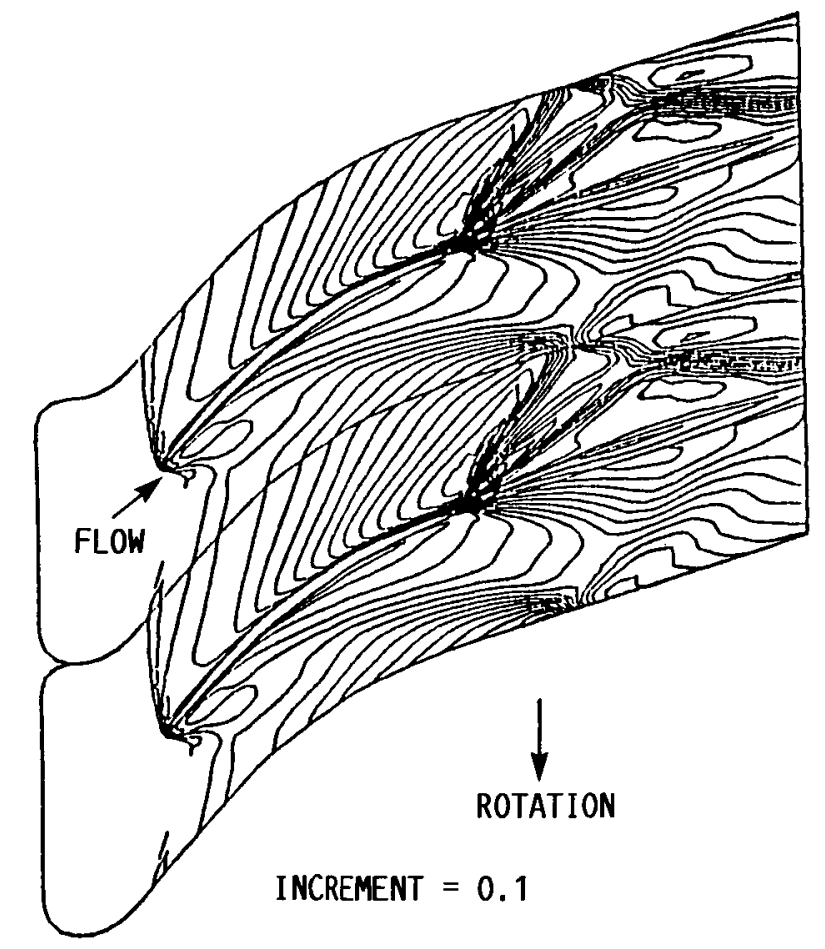

MACH NUMBER CONTOURS

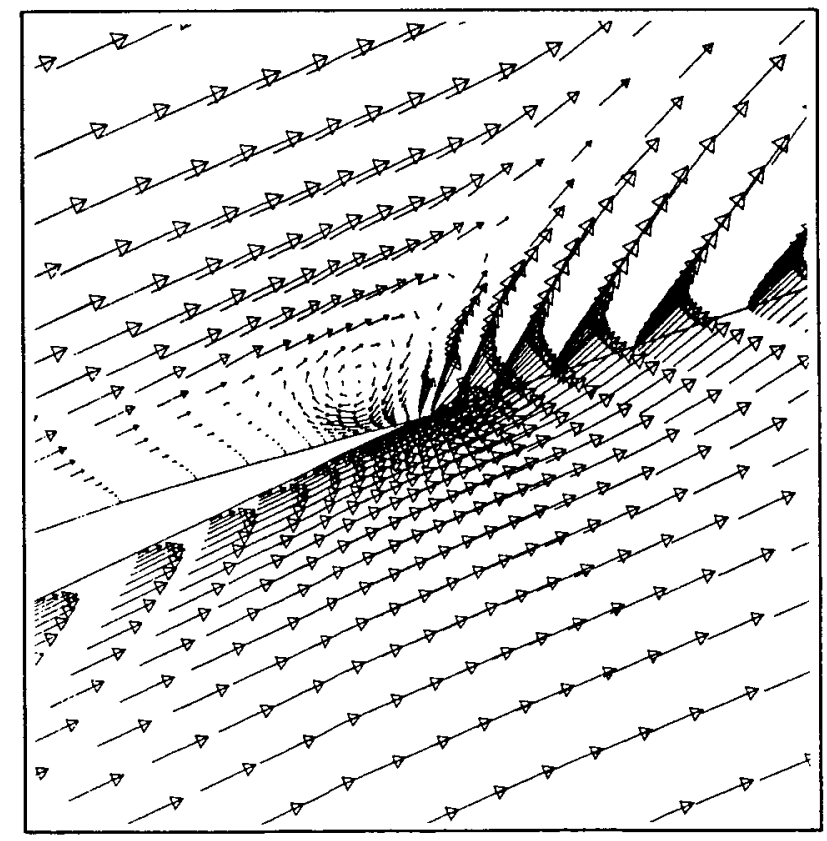

VECTOR PLOT AT TRAILING EDGE

FIGURE 3.- RESULTS OBTAINED WITH THE RVCO3 CODE ON AN INITIAL BLADE SHAPE USED TO CHECK CODES FOR SUPERSONIC AXIAL INFLOW: INLET AXIAL MACH NUMBER OF 1.5 AND TIP SPEED OF $488 \mathrm{M} / \mathrm{SEC}$. 


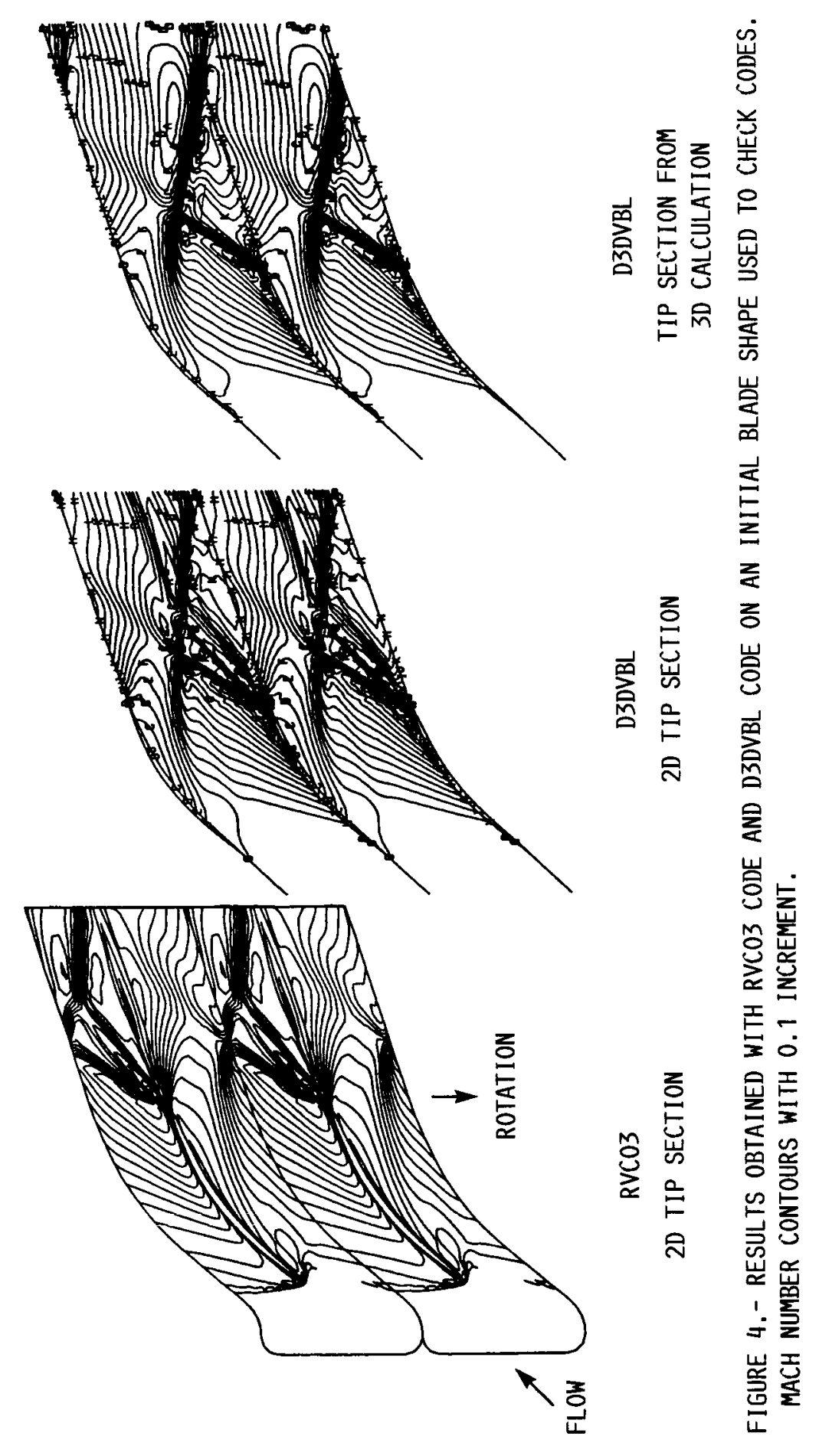




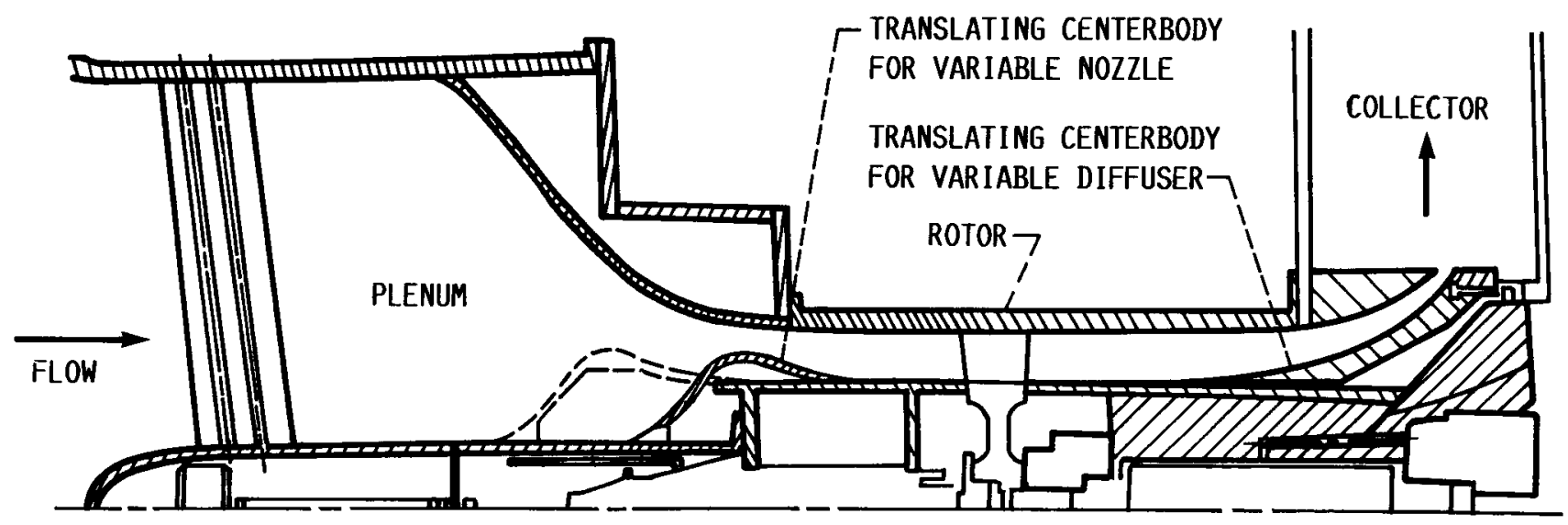

FIGURE 5.- PROPOSED TEST FACILITY FOR SUPERSONIC THROUGH FLOW FAN ROTOR. 


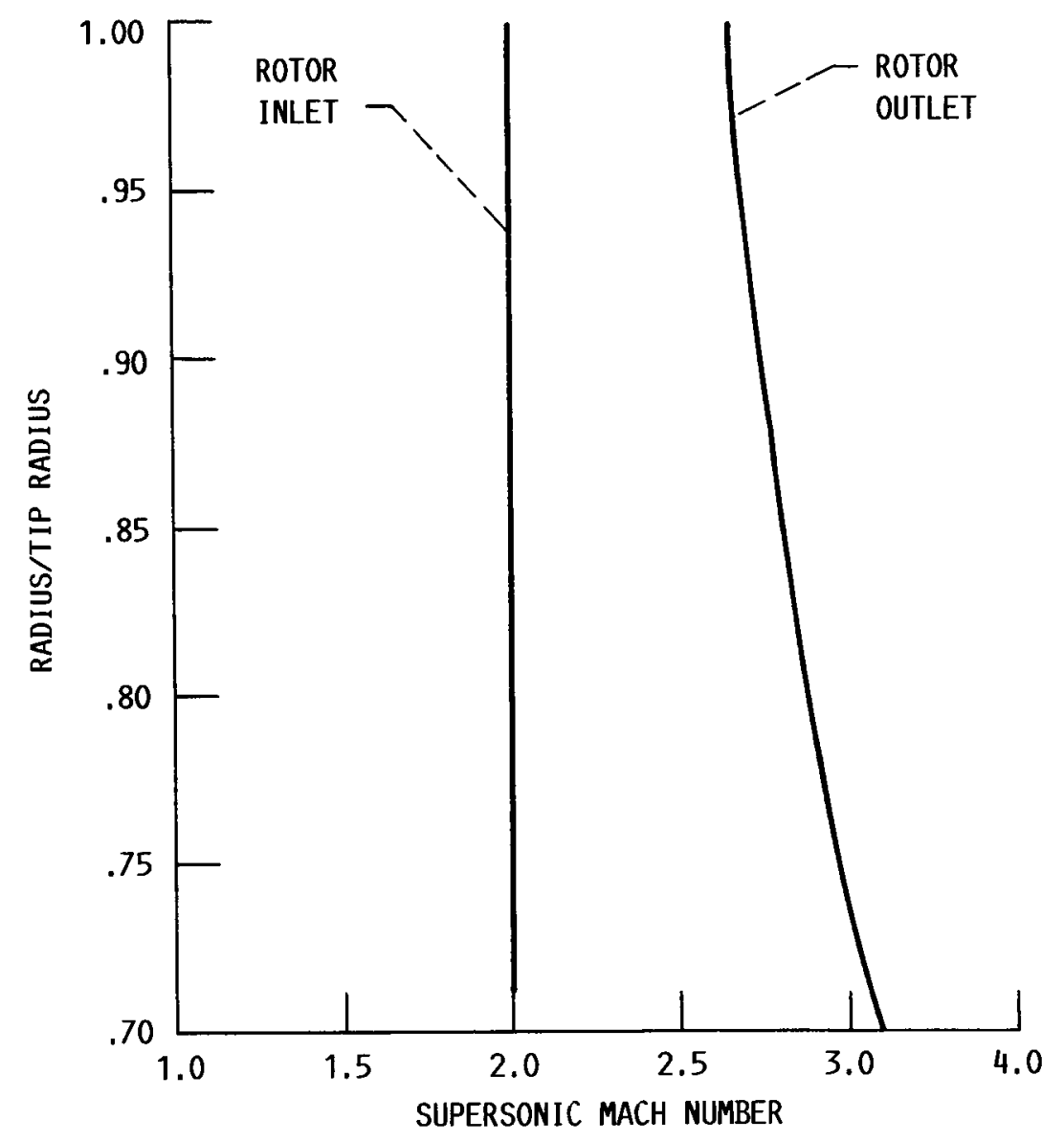

FIGURE 6.- CALCULATED DISTRIBUTIONS OF SUPERSONIC ABSOLUTE MACH NUMBER THROUGH FAN ROTOR USING THE CDP CODE. 


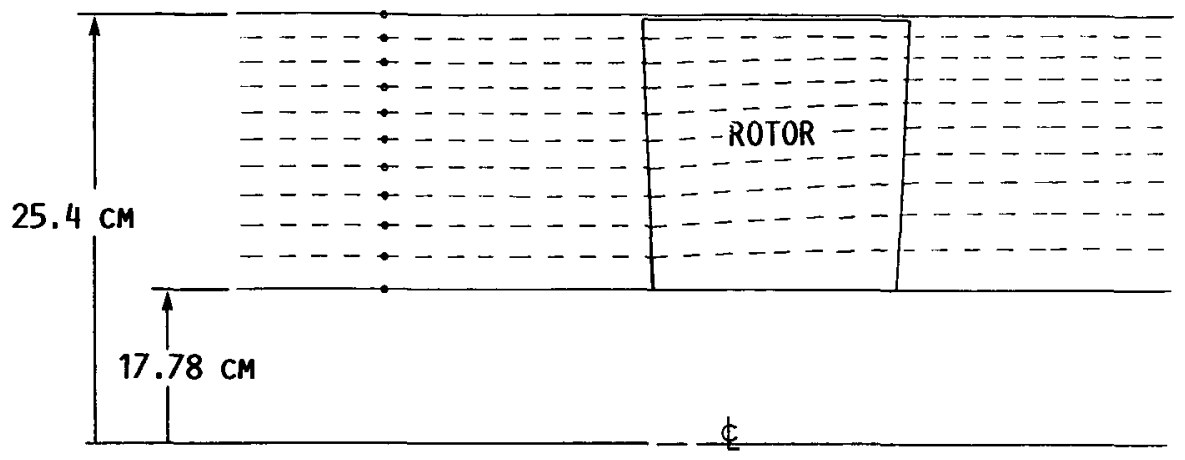

FIGURE 7.- FAN FLOWPATH WITH ROTOR AND CALCULATED STREAMLINES FROM THE CDP DESIGN CODE.

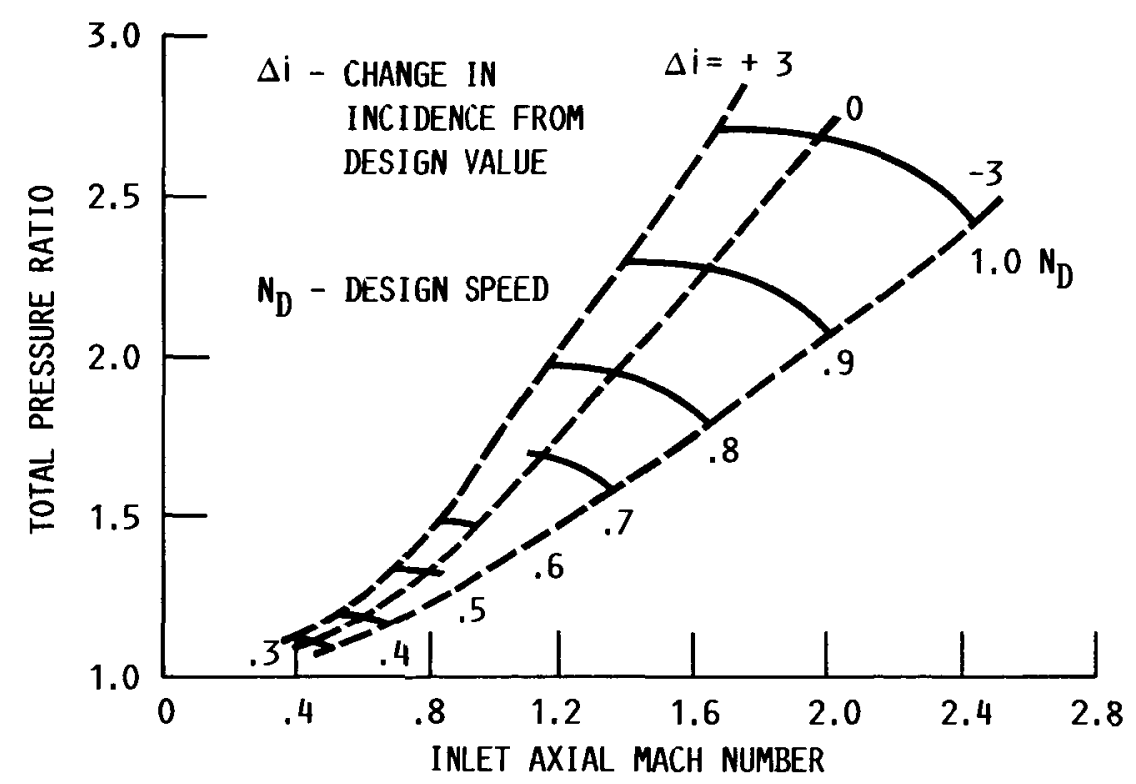

FIGURE 8. - FAN STAGE OFF-DESIGN PERFORMANCE PREDICTION FROM THE STGSTK MEANLINE CODE. 


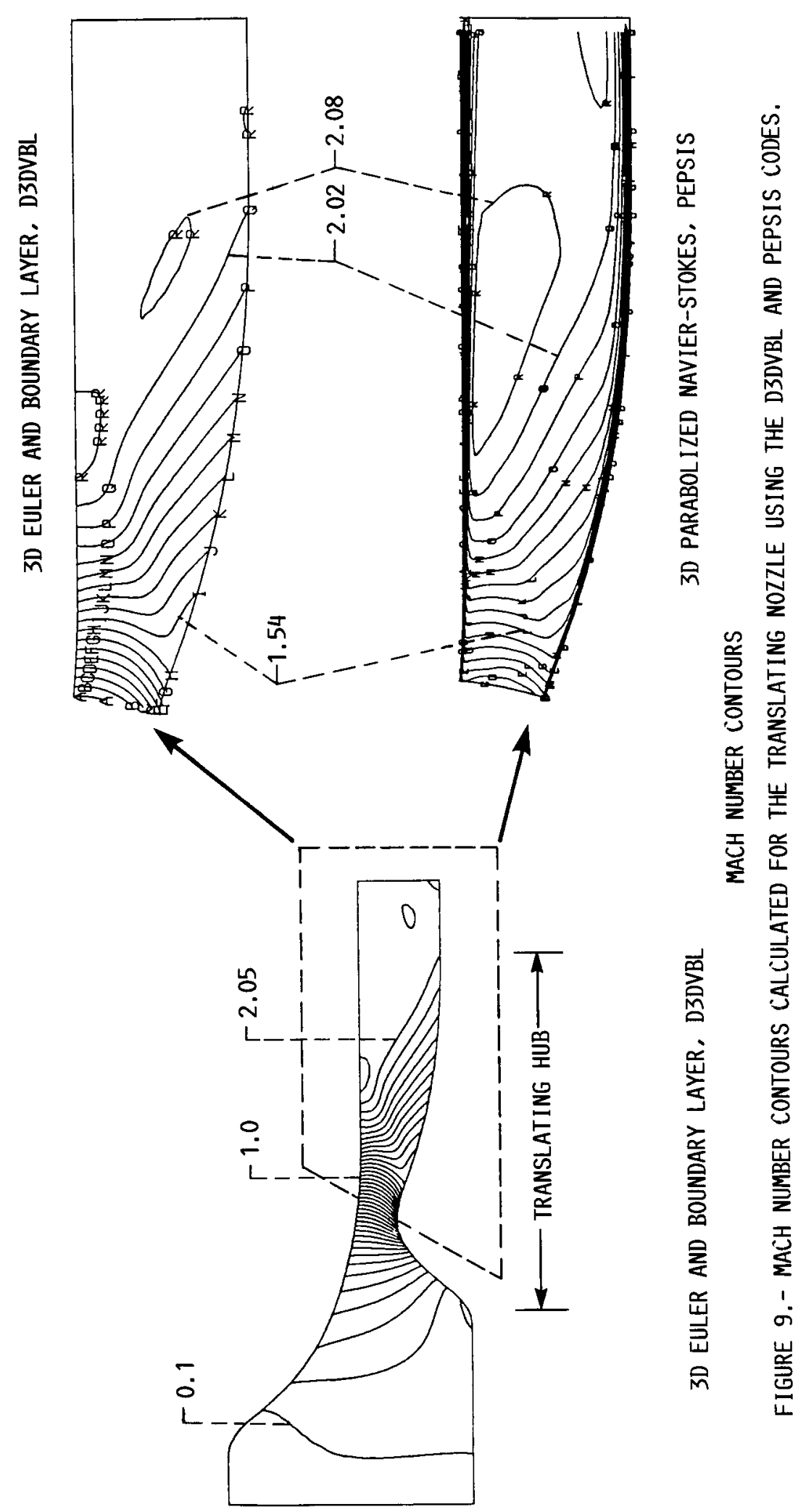



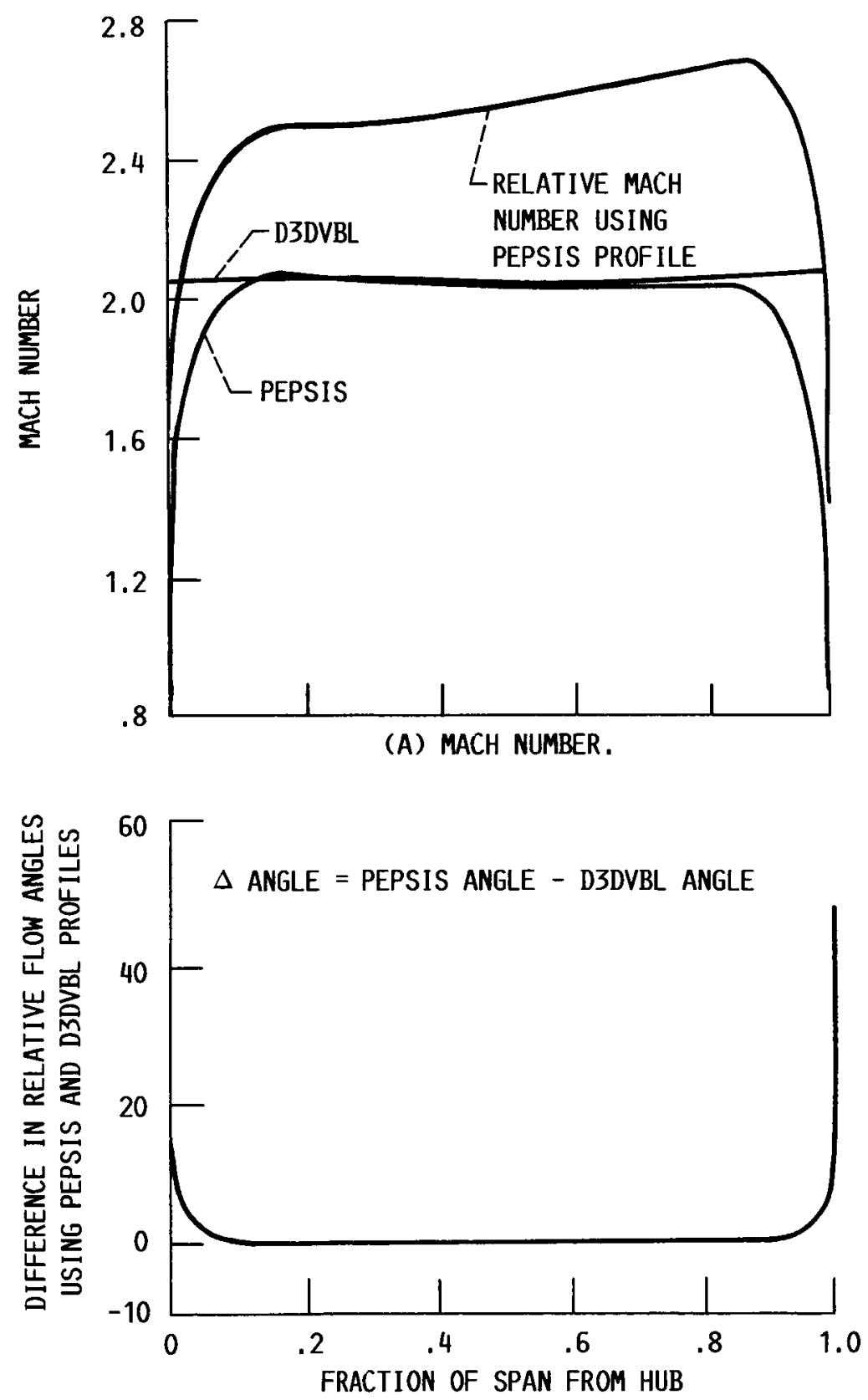

(B) EFFECT OF VISCOUS PROFILE ON RELATIVE FLOW ANGLE.

FIGURE 10. - CALCULATED CONDITIONS AT THE FAN FACE USING THE D3DVBL AND PEPSIS CODES. 

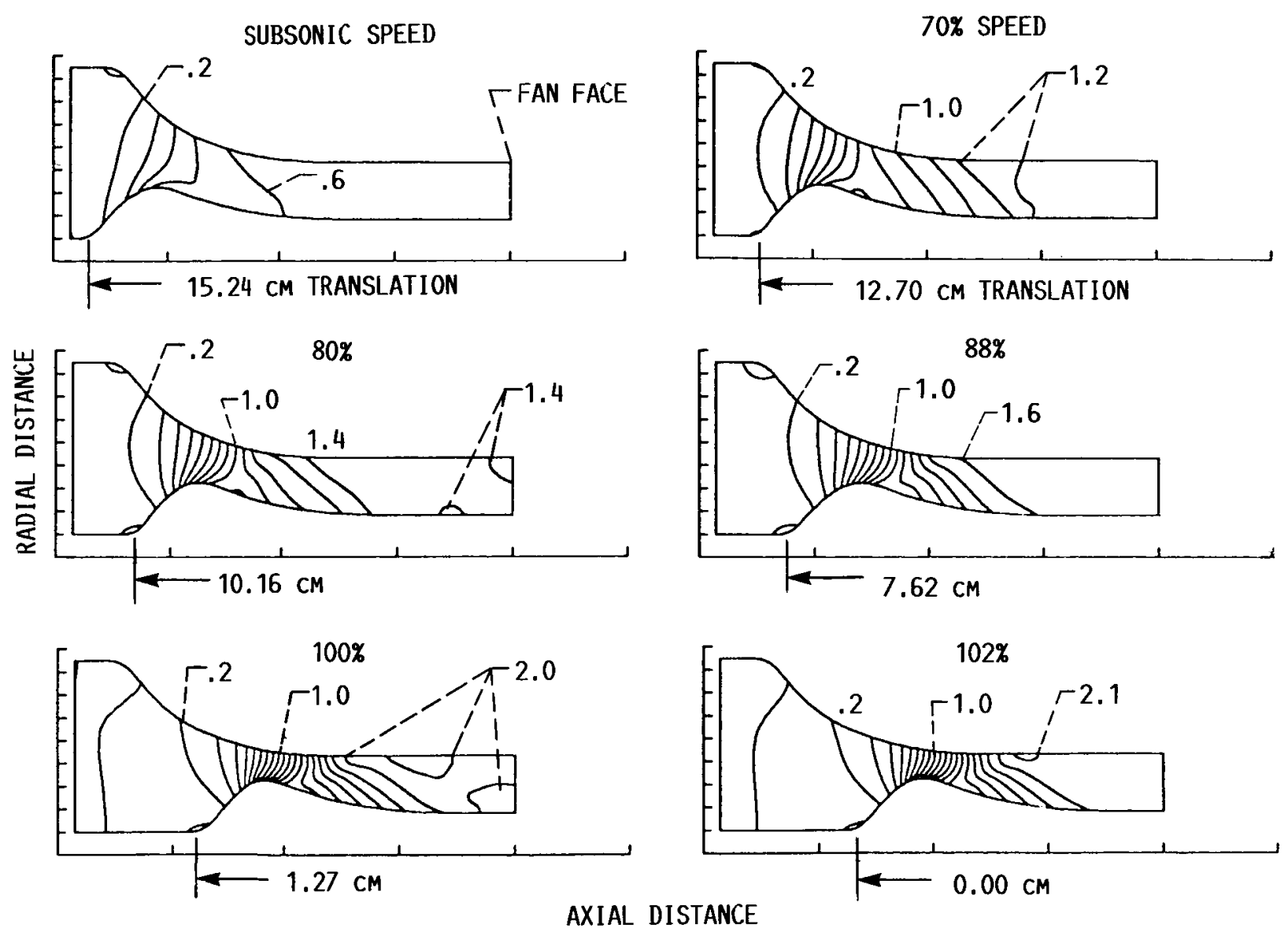

FIGURE 11.- MACH NUMBER CONTOURS CALCULATED FOR THE TRANSLATING NOZZLE WITH THE D3DVBL CODE. 


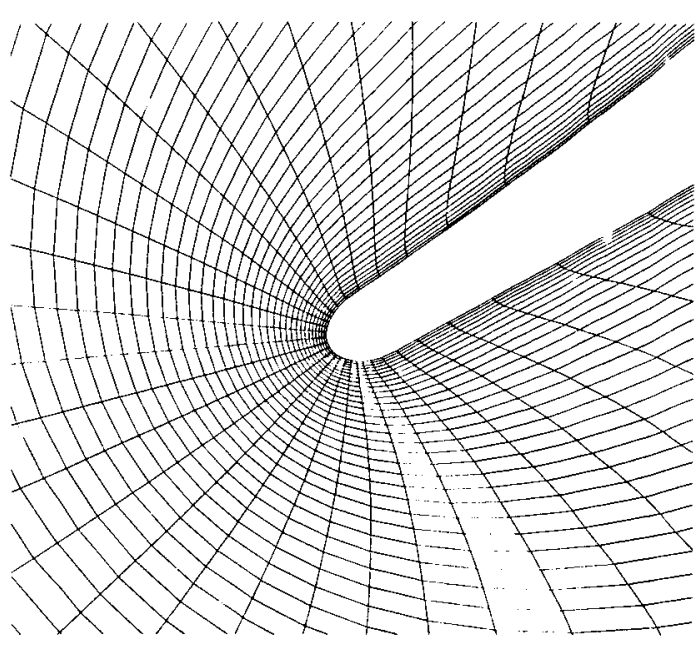

(A) GRID LINES AT LEADING EDGE.

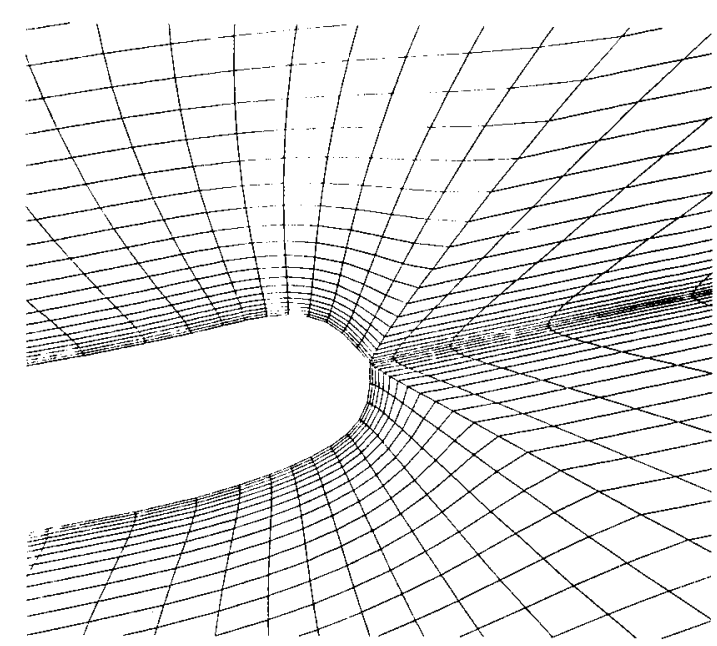

(B) GRID LINES AT TRAILING EDGE.

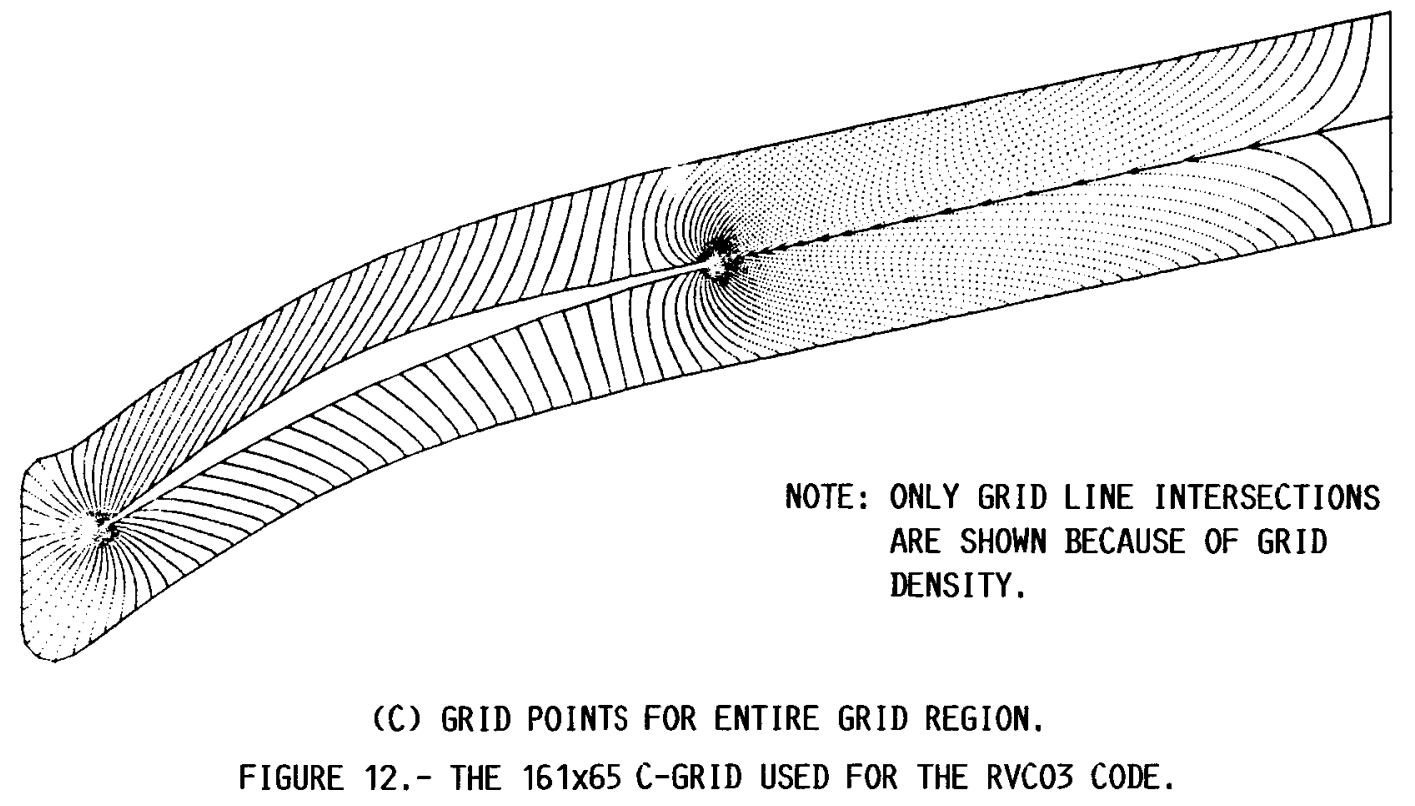




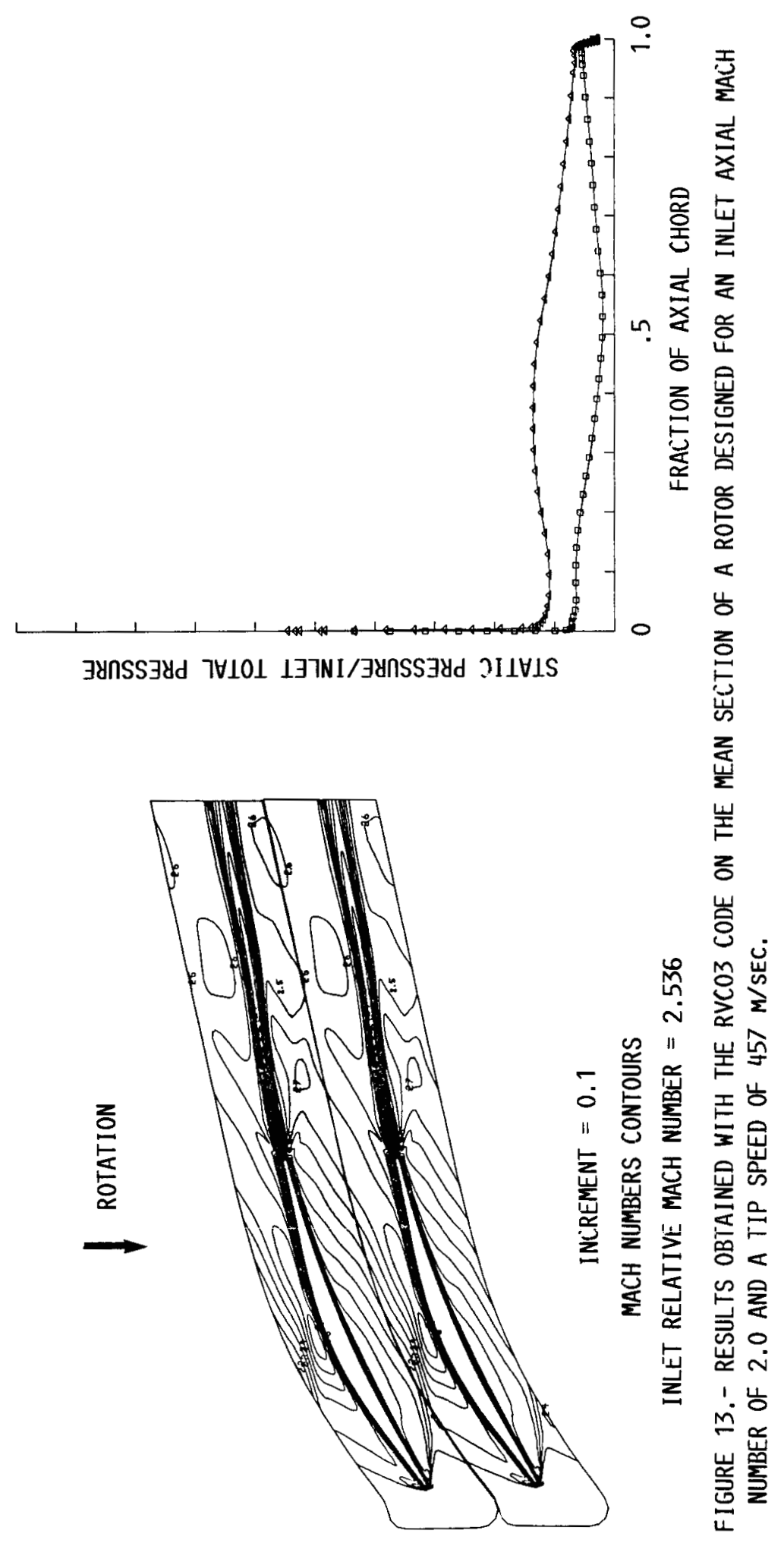




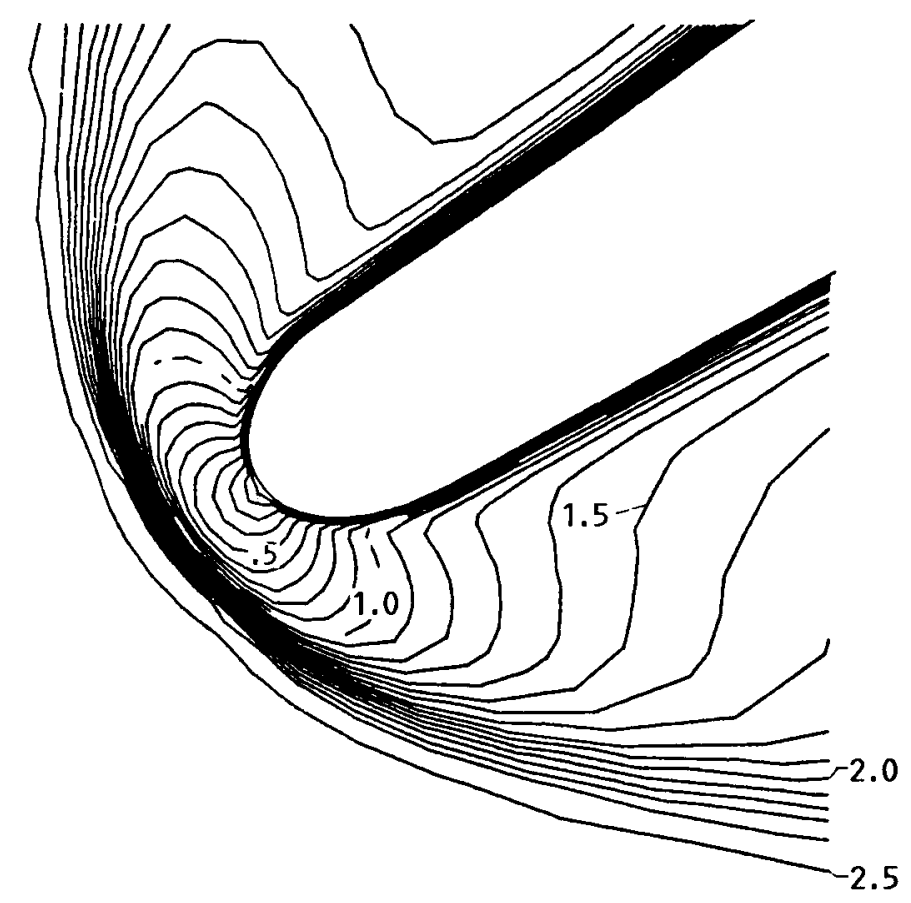

(A) MACH NUMBER CONTOURS AT LEADING EDGE.

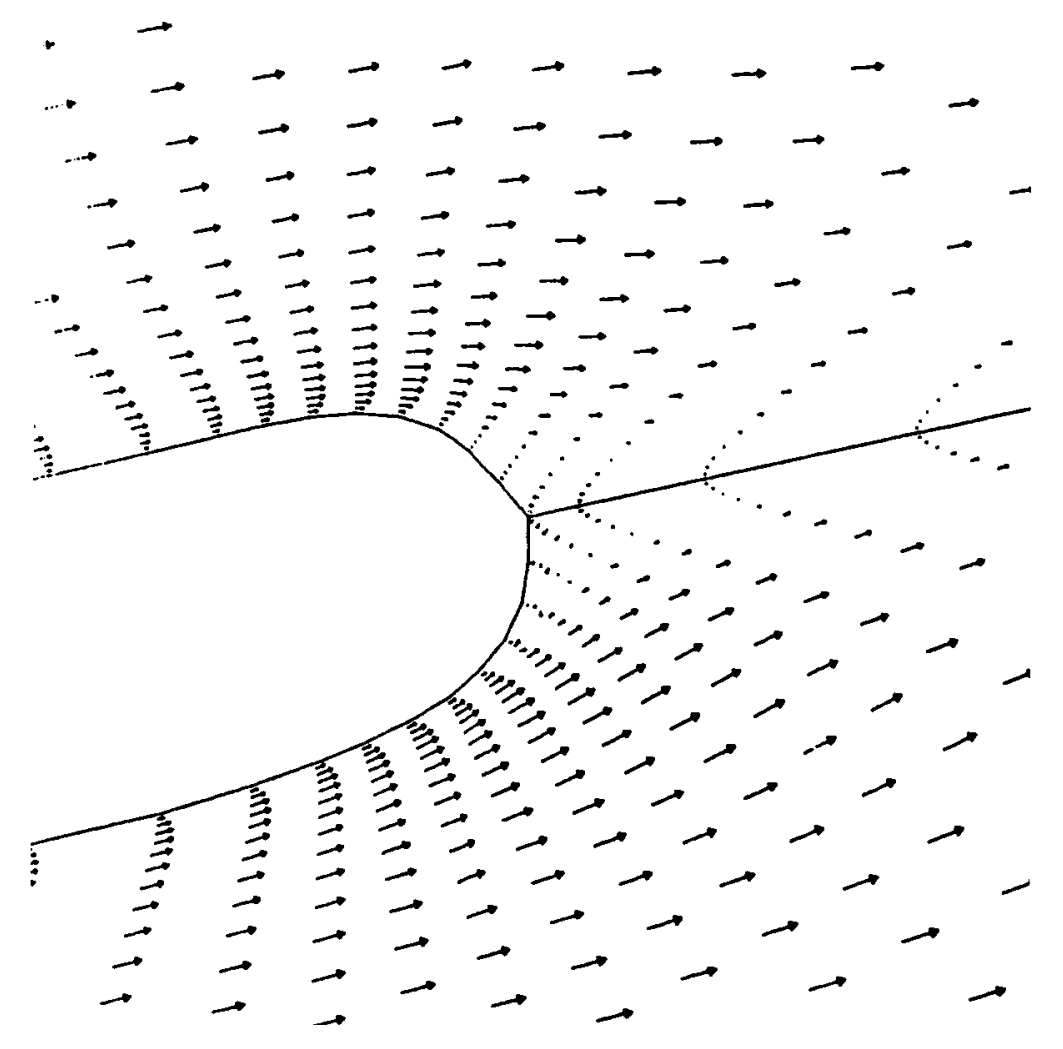

(B) VELOCITY VECTORS AT TRAILING EDGE.

FIGURE 14.- DETAILED FLOW ANALYSIS BY THE RVCO3 CODE OF THE FAN ROTOR AT THE MEAN SECTION. 




FIGURE 15. - COMPARISON OF STATIC PRESSURES AT MEAN SECTION OF THE FAN ROTOR CALCULATED WITH THE RVCO3 AND D3DVBL CODES FOR THE 2D SECTION AND CALCULATED WITH THE D3DVBL CODE FOR THE FULL 3D BLADE. 


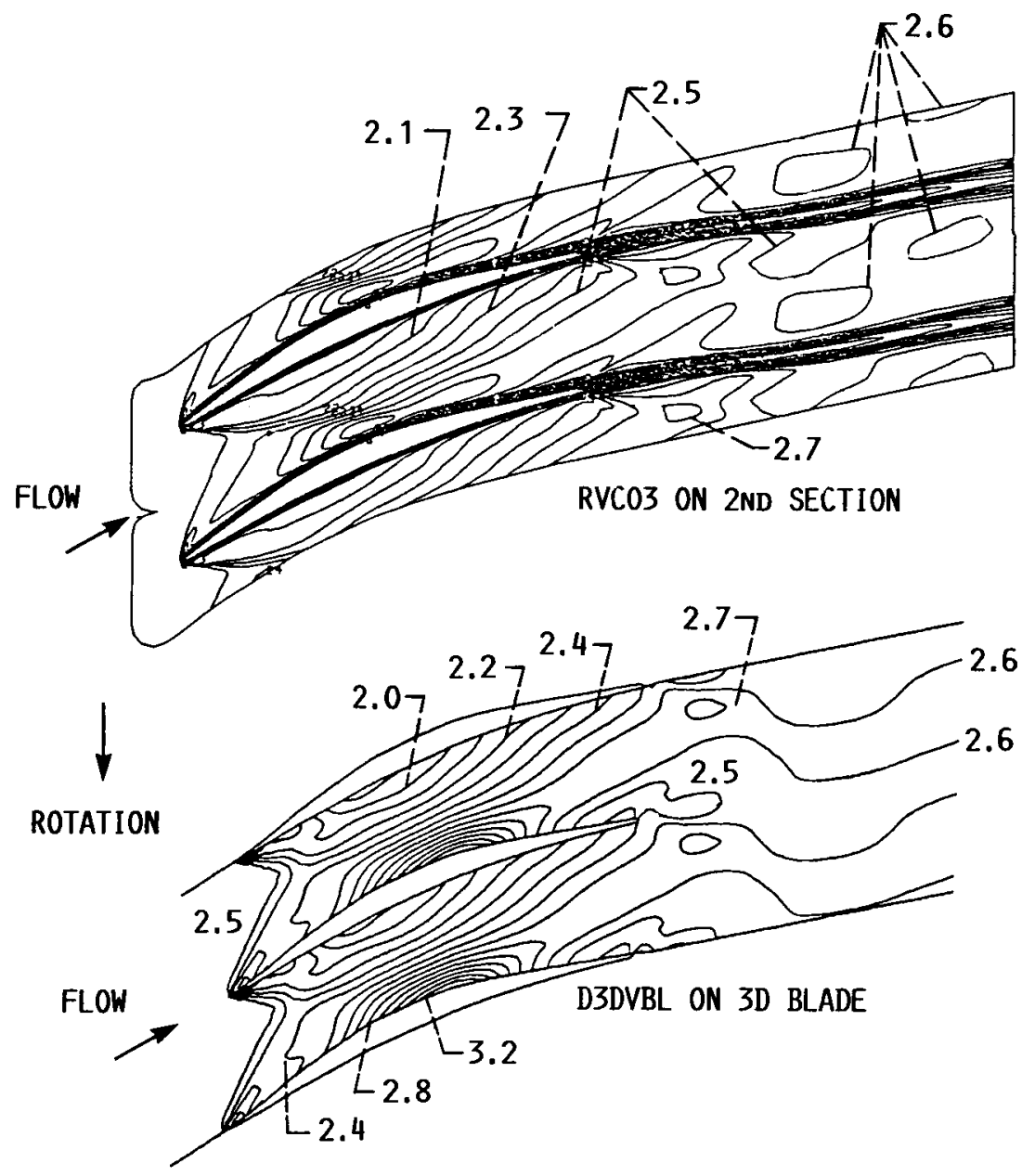

FIGURE 16.- COMPARISON OF CALCULATED RELATIVE MACH NUMBER CONTOURS ON THE MEAN SECTION USING THE RVCO3 AND D3DVBL CODE. 


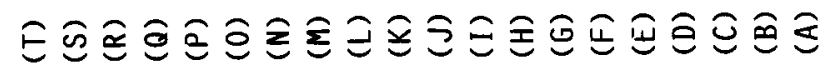

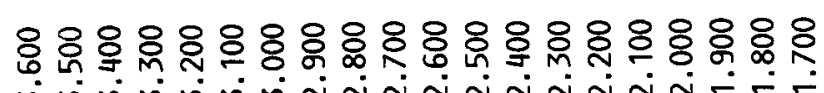
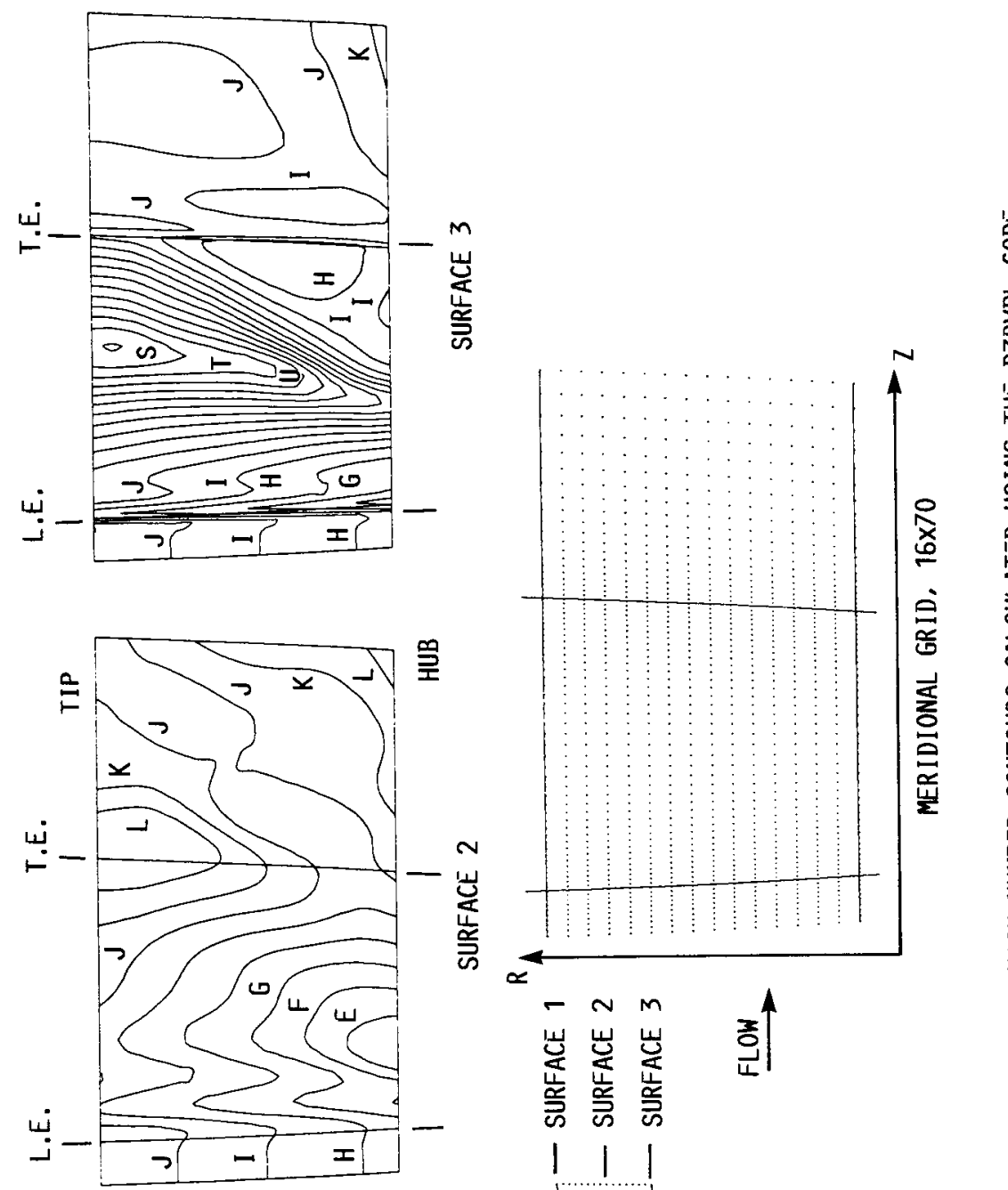

붕

謽

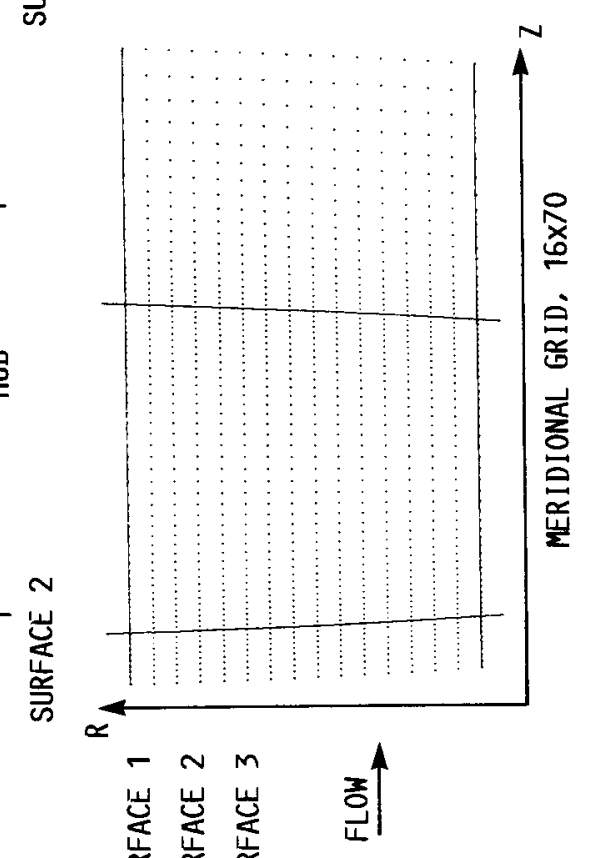

|

商

表

远

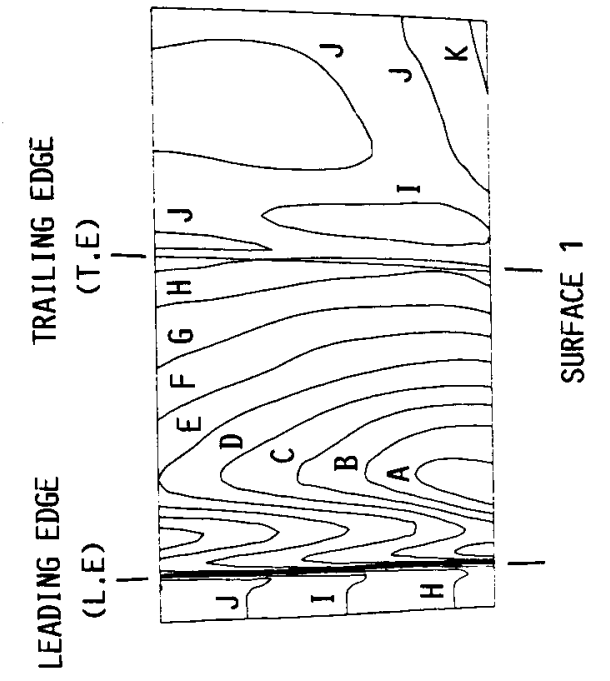

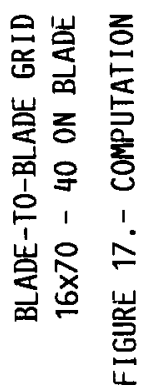




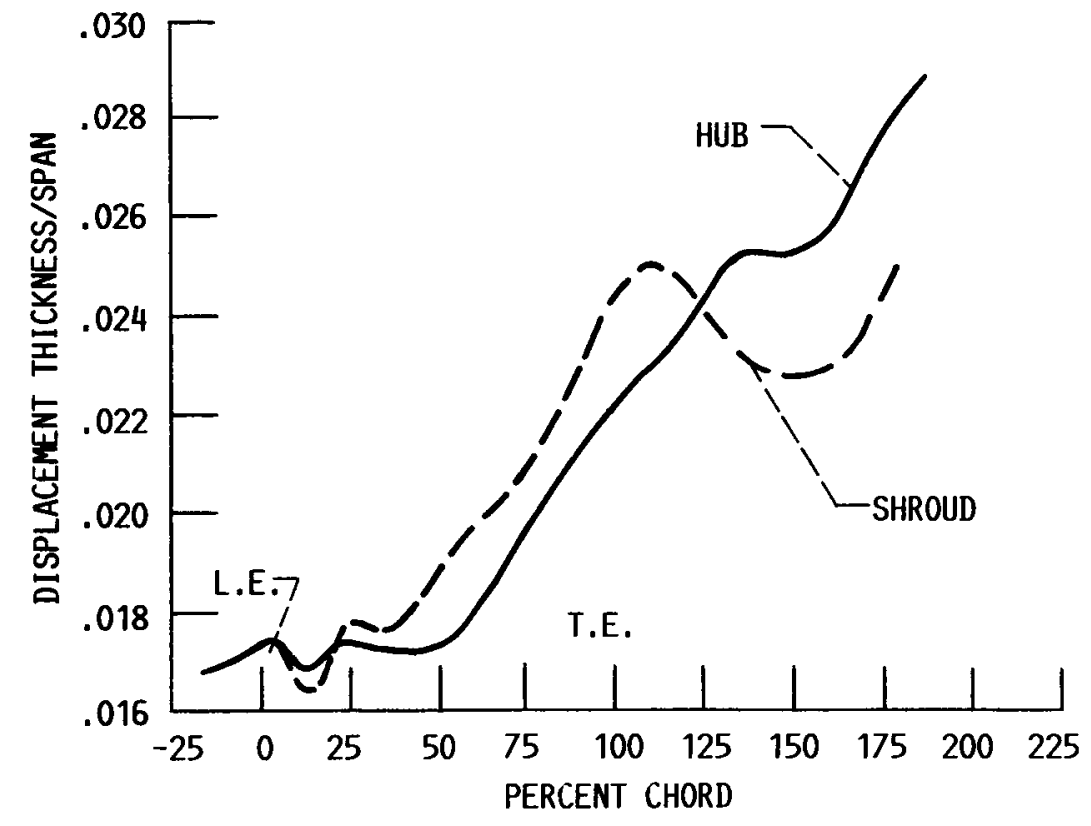

FIGURE 18. - GROWTH OF DISPLACEMENT THICKNESS ALONG THE MID-GAP LINE AT HUB AND SHROUD FOR THE FAN ROTOR AS CALCULATED WITH THE D3DVBL CODE. 


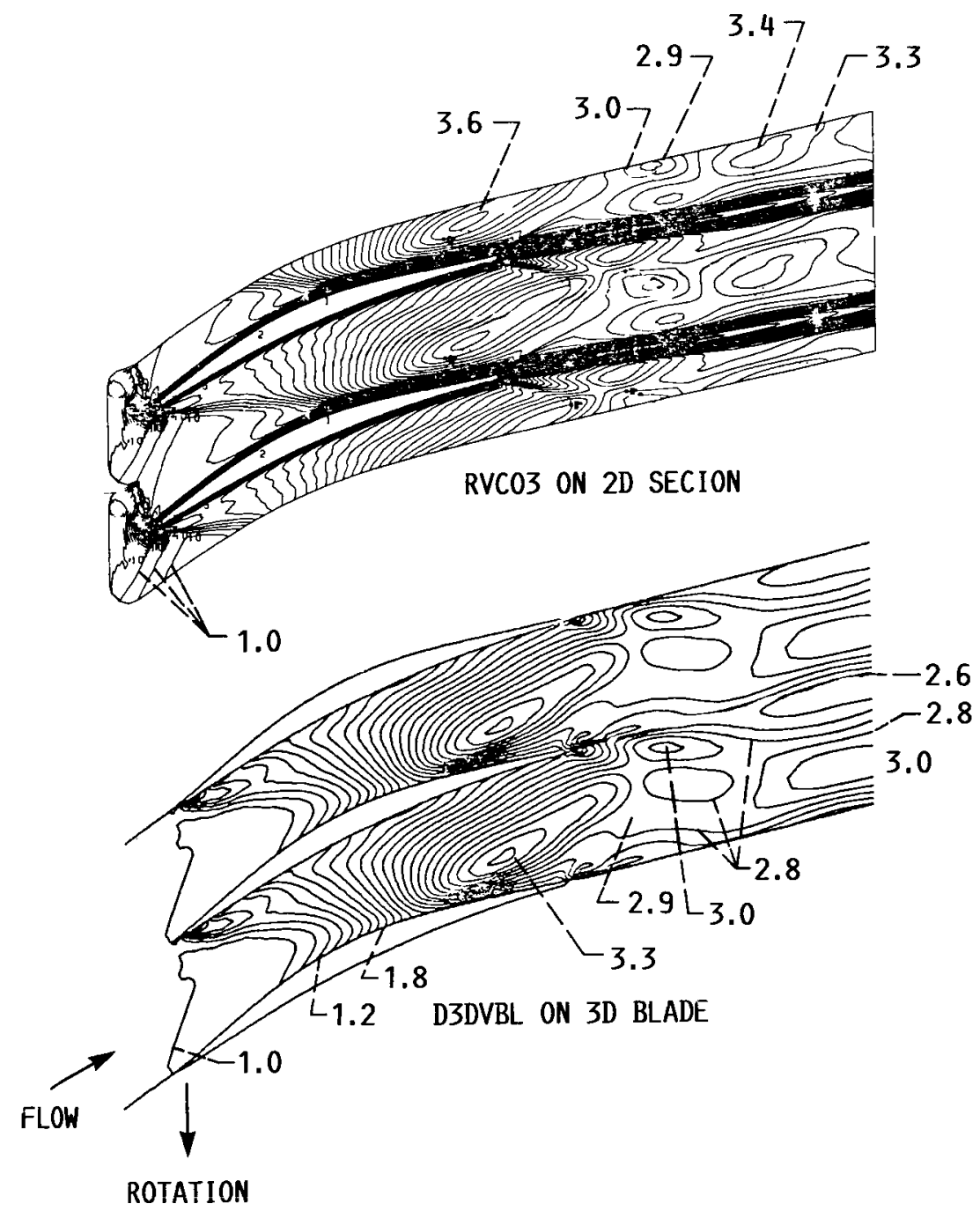

FIGURE 19. - COMPARISON OF ABSOLUTE TOTAL PRESSURE RATIO CALCULATED WITH THE RVCO3 AND D3DVBL CODES FOR THE ROTOR MEAN SECTION. 


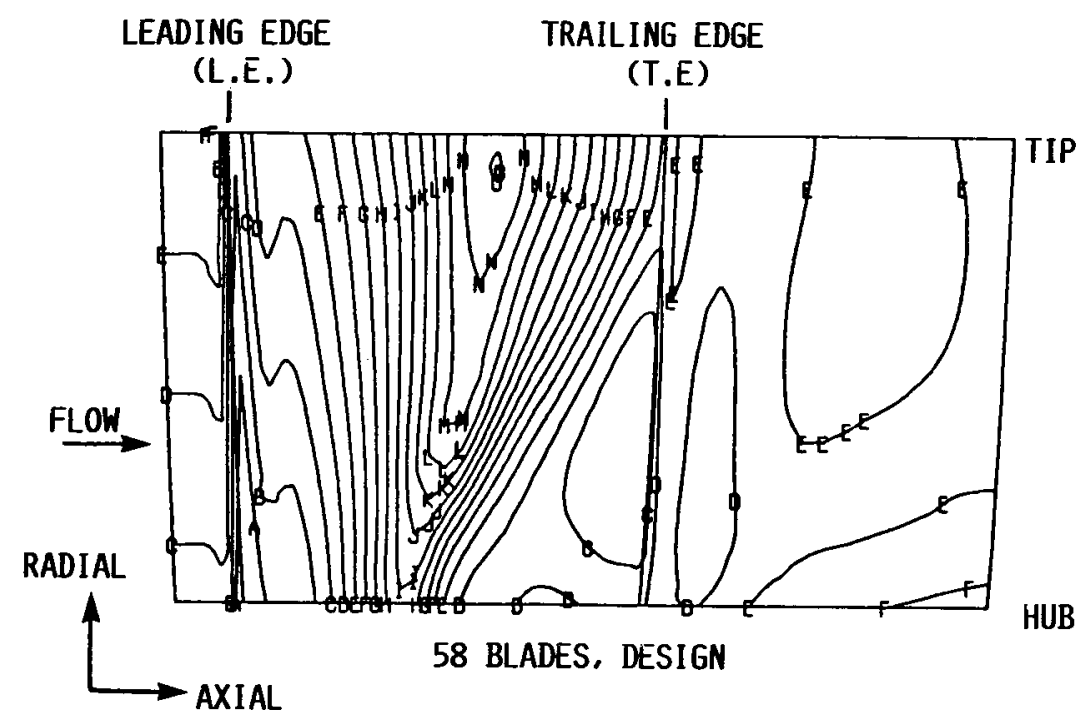

4.000 (S)

$3.900 \quad$ (R)

$3.800 \quad(Q)$

$3.700 \quad(P)$

$3.600 \quad(0)$

3.500 (N)

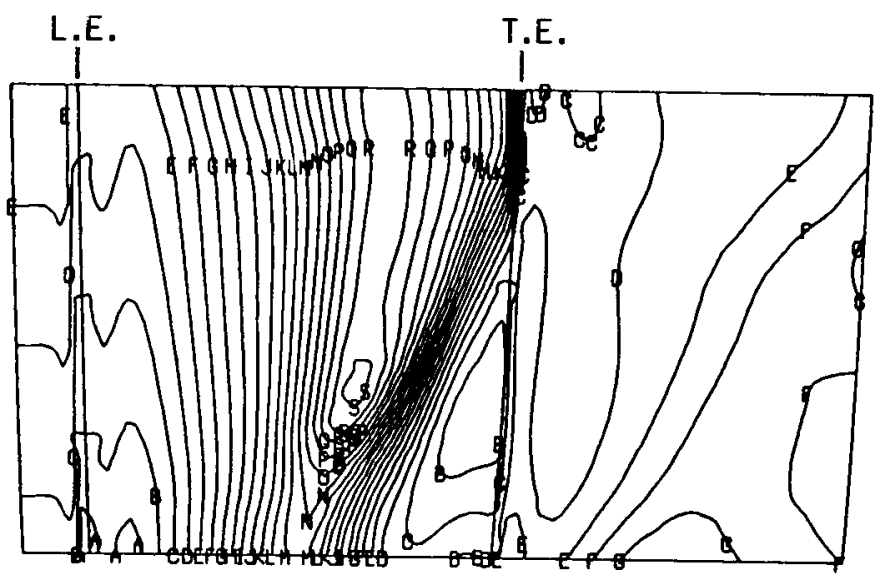

$3.400 \quad(M)$

$3.300 \quad(L)$

$3.200 \quad$ (K)

$3.100 \quad$ (J)

3.000 (I)

$2.900 \quad(H)$

$2.800 \quad$ (G)

$2.700 \quad(F)$

2.600 (E)

2.500 (D)

$2.400 \quad$ (C)

2.300 (B)

2.200 (A)

54 BLADES

FIGURE 20.- RESULTS FROM THE D3DVBL CODE SHOWING THE EFFECT OF REDUCING BLADE NUMBER ON THE RELATIVE MACH NUMBER CONTOURS ON THE MERIDIONAL PROJECTION OF THE SUCTION SURFACE. 


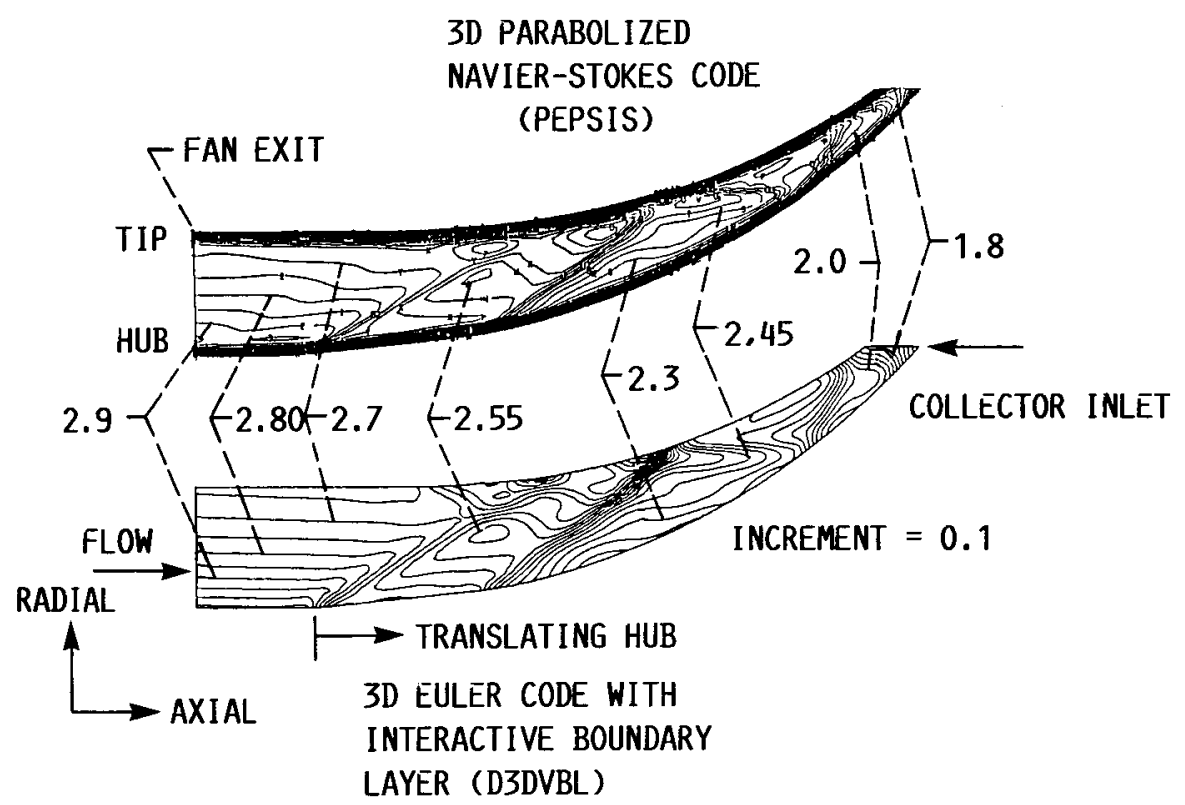

FIGURE 21.- MACH NUMBER CONTOURS CALCULATED WITH THE D3DVBL AND PEPSIS CODES FOR THE TRANSLATING DIFFUSER AT THE DESIGN SETTING. FLOW ANGLE FROM AXIAL IS $27^{\circ}$ AT THE HUB AND $21^{\circ}$ AT TIP. 


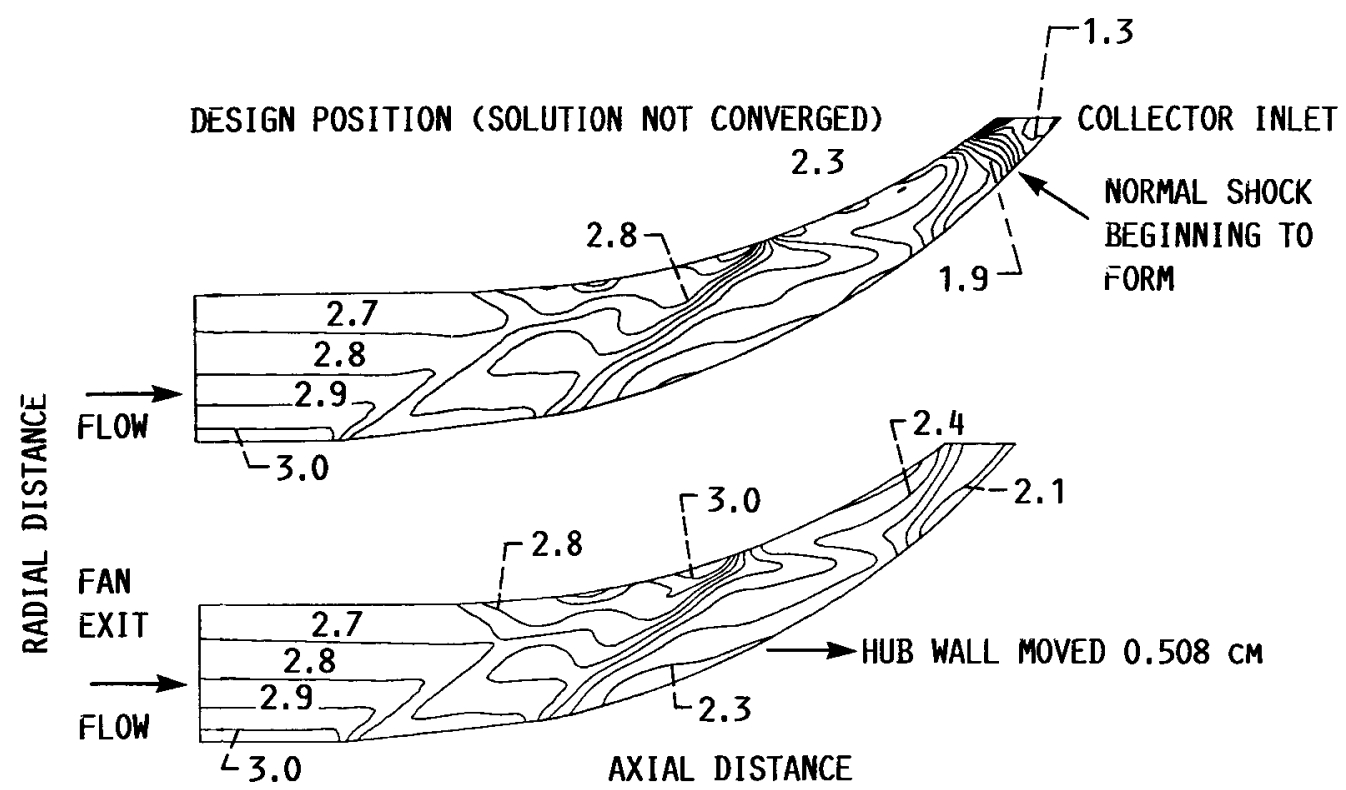

FIGURE 22. - MACH NUMBER CONTOURS CALCULATED WITH THE D3DVBL CODE SHOWING THE EFFECT OF DOUBLING THE FAN EXIT BLOCKAGE AND THE RELIEF GAINED BY TRANSLATING THE INNER WALL.

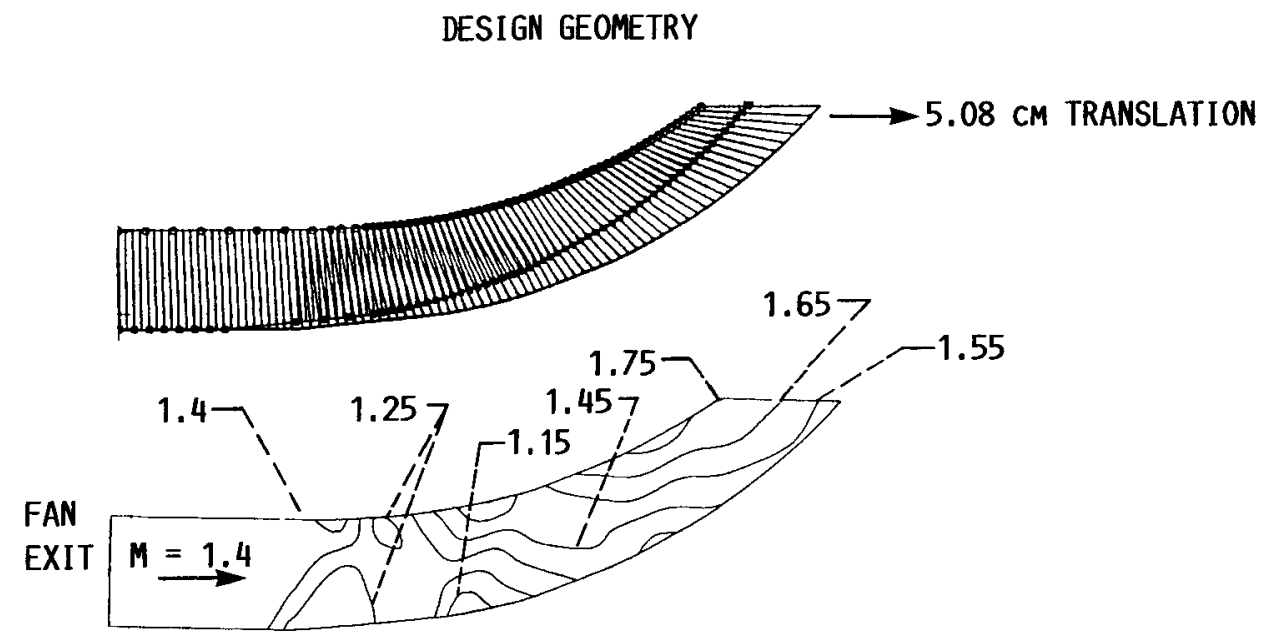

FIGURE 23.- MACH NUMBER CONTOURS CALCULATED WITH THE D3DVBL CODE SHOWING TRANSLATION REQUIRED TO MAINTAIN SUPERSONIC FLOW FOR OPERATION AT AN INLET MACH NUMBER OF 1.4. 




*For sale by the National Technical Information Service, Springfield, Virginia 22161 